University of Wollongong

Research Online

Australian Institute for Innovative Materials -

Papers

Australian Institute for Innovative Materials

$1-1-2011$

\title{
The molecular level modification of surfaces: From self-assembled monolayers to complex molecular assemblies
}

J Justin Gooding

University of New South Wales, justin.gooding@unsw.edu.au

Simone Ciampi

University of New South Wales, sciampi@uow.edu.au

Follow this and additional works at: https://ro.uow.edu.au/aiimpapers

Part of the Engineering Commons, and the Physical Sciences and Mathematics Commons

Research Online is the open access institutional repository for the University of Wollongong. For further information contact the UOW Library: research-pubs@uow.edu.au 


\title{
The molecular level modification of surfaces: From self-assembled monolayers to complex molecular assemblies
}

\author{
Abstract \\ The modification of surfaces with self-assembled monolayers (SAMs) containing multiple different \\ molecules, or containing molecules with multiple different functional components, or both, has become \\ increasingly popular over the last two decades. This explosion of interest is primarily related to the ability \\ to control the modification of interfaces with something approaching molecular level control and to the \\ ability to characterise the molecular constructs by which the surface is modified. Over this time the level \\ of sophistication of molecular constructs, and the level of knowledge related to how to fabricate \\ molecular constructs on surfaces have advanced enormously. This critical review aims to guide \\ researchers interested in modifying surfaces with a high degree of control to the use of organic layers. \\ Highlighted are some of the issues to consider when working with SAMs, as well as some of the lessons \\ learnt (169 references). 2011 The Royal Society of Chemistry.

\section{Keywords} \\ self, molecular, assembled, level, monolayers, complex, assemblies, modification, surfaces

\section{Disciplines} \\ Engineering | Physical Sciences and Mathematics

\section{Publication Details} \\ Gooding, J. Justin. \& Ciampi, S. (2011). The molecular level modification of surfaces: From self- \\ assembled monolayers to complex molecular assemblies. Chemical Society Reviews, 40 (5), 2704-2718.
}




\section{The molecular level modification of surfaces: from self-assembled monolayers to complex molecular assemblies}

\author{
J. Justin Gooding* and Simone Ciampi \\ Received 12th October 2010 \\ DOI: $10.1039 / \mathrm{c0cs00139b}$
}

The modification of surfaces with self-assembled monolayers (SAMs) containing multiple different molecules, or containing molecules with multiple different functional components, or both, has become increasingly popular over the last two decades. This explosion of interest is primarily related to the ability to control the modification of interfaces with something approaching molecular level control and to the ability to characterise the molecular constructs by which the surface is modified. Over this time the level of sophistication of molecular constructs, and the level of knowledge related to how to fabricate molecular constructs on surfaces have advanced enormously. This critical review aims to guide researchers interested in modifying surfaces with a high degree of control to the use of organic layers. Highlighted are some of the issues to consider when working with SAMs, as well as some of the lessons learnt (169 references).

\section{Introduction}

The assembly of entirely molecular building blocks into functional devices is sometimes called molecular nanotechnology to differentiate it from nanotechnology where devices are fabricated using nanomaterials. ${ }^{1}$ Although a somewhat artificial distinction, the term molecular nanotechnology does

School of Chemistry, The University of New South Wales, Sydney, NSW 2052, Australia.E-mail: Justin.gooding@unsw.edu.au; Fax: + 6129385 6141; Tel: + 61293855384

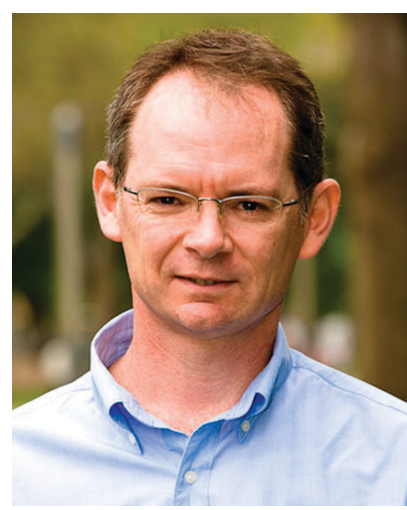

J. Justin Gooding
Professor Justin Gooding is an ARC Australian Professorial Fellow. He graduated with a BSc (Hons) from Melbourne University in 1988 and a DPhil from Oxford University. Subsequently he undertook a post-doctoral appointment at the Institute of Biotechnology in Cambridge University. He accepted a lectureship at UNSW in 1999 and was promoted to full professor in 2006. He was a recipient of a 2004 NSW Young Tall Poppy award, the 2007 RACI Lloyd Smythe Medal for Analytical Chemistry, and the 2009 Eureka Prize for Scientific Research. His research interests are in surface modification using self-assembled monolayers for sensing, molecular electronics and biomaterials applications. confer the notion that truly molecular devices are being fabricated. As with many nanodevices, frequently such molecular constructs will be assembled onto a surface. The surface confinement of molecular assemblies is often necessary to know where the devices are, as a means to communicate with the devices, or to allow the activity of the molecular device to be monitored. As a consequence, the modification of surfaces with molecular assemblies is one of the foundations of molecular nanotechnology. As with nanotechnology in general, there has been intense interest in developing molecular assemblies on surfaces for a host of applications, including

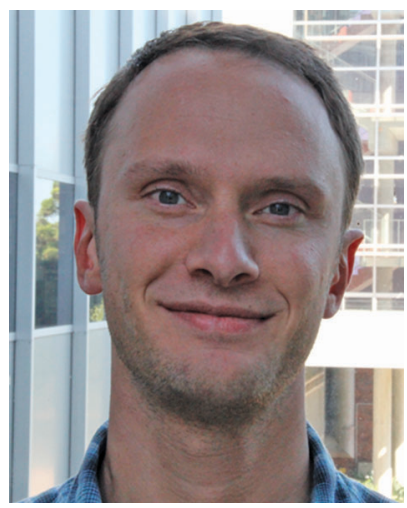

Simone Ciampi
Simone Ciampi graduated with a BSc (Hons) in Industrial Biotechnology from Universita' di Modena e Reggio Emilia in 2004 after working with Dr Luca Forti on synthetic analogs of resveratrol. In 2006 he joined the group of Professor Justin Gooding at University of New South Wales, where he has been ever since. In 2010 he obtained his doctorate studying the modification of silicon electrodes for electrochemical applications. $H$ is research interests are in organic reactions applied to surface science and the electrochemical application of modified silicon and porous silicon electrodes. 
sensors and biochips, ${ }^{2,3}$ photovoltaics, ${ }^{4,5}$ fuel cell, ${ }^{6}$ biomaterials, ${ }^{7}$ and molecular electronics, ${ }^{4,8,9}$ as well as to provide fundamental understanding of electron transfer, ${ }^{10}$ controlling reactions at surfaces, ${ }^{11}$ and tailoring surface properties. ${ }^{12}$ Among the many exciting developments, a number of rather sophisticated molecular assemblies have been developed that not only involve organic and organometallic molecules, but also nanomaterials and/or biomolecules., ${ }^{3,13}$ A couple of examples of some of the more complicated interfaces are shown in Fig. 1. ${ }^{14,15}$ As can be seen from these schemes, quite sophisticated molecular devices, with multiple different functional components, can be assembled on a surface; a surface which may also contain additional chemical functionalities. There are, of course, many other examples of simpler interfaces, but the examples in Fig. 1 exemplify both the complexity that has been achieved and the control an interfacial designer must master when developing surface bound molecular devices. Furthermore, these examples also indicate that to achieve a molecular-level control over the modification of the interface, the use of self-assembled monolayers, or thin films, is typically required. There are, however, a myriad of choices the designer of molecular assemblies on surfaces must make. The choices that must be made start from the type of substrate upon which the device will be assembled, which will in turn dictate the type of the self-assembly system that can be employed. Obvious aspects with regards to the choice of substrate will relate to whether it needs to be conducting, transparent or compatible with microfabrication techniques. Less obvious choices relate, for example, either to surface roughness, ${ }^{16}$ to its ability to be precisely structured, or to its rigidity. The choice of the particular self-assembly system also depends on the level of stability and order that is required. For example, aryl diazonium salt derived layers on gold surfaces provide more stable layers than the alkanethiol self-assembly system, ${ }^{17}$ but with far less control over the molecular organisation of the layers. ${ }^{3}$ With layers more complicated than just a single component, as for example with the systems shown in Fig. 1, there are a multitude of further decisions to be made. For example, should the self-assembly molecule be completely synthesized prior to assembly onto the surface, or should the different parts of the envisioned molecular assembly be coupled onto the surface in a step-wise process? If a monolayer with multiple components is to be formed, then, how should this be done? If a step-wise procedure is to be employed, what coupling chemistry should be used?

The answers to all these, and related questions, depend very much on the intended applications of the system under investigation. The purpose of this critical review is to provide the reader with the information to start answering these questions. This review will draw from both our own experience in developing molecular level surface modification strategies for sensing and electron transfer studies, as well as from the work of others. Initially, it will cover different self-assembly systems for forming basic layers, discussing their pros and cons. Subsequently, the issue of whether the molecular a)

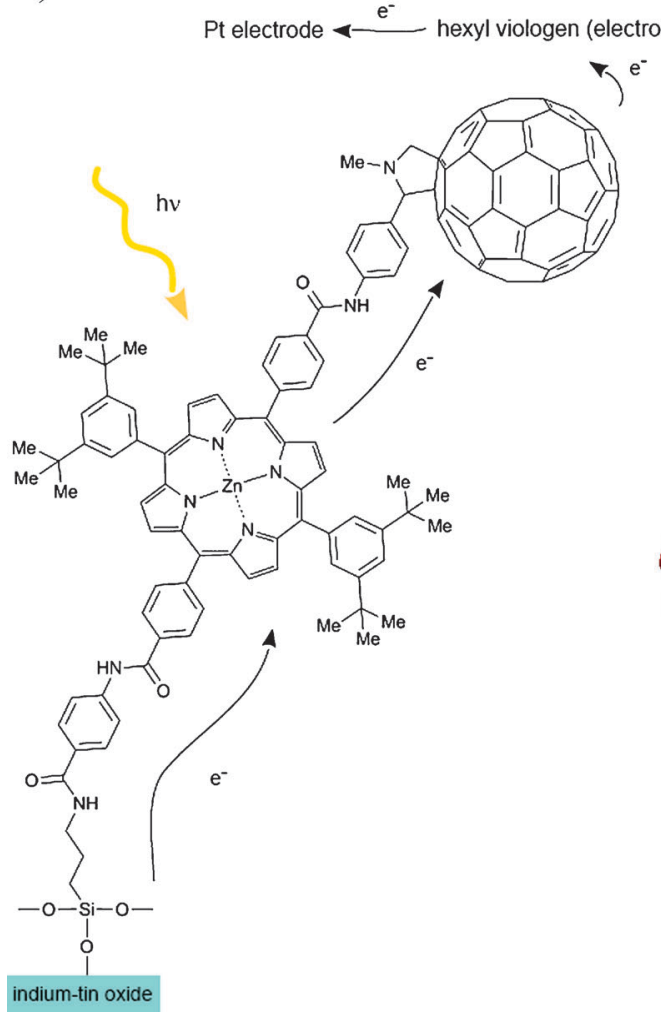

b)

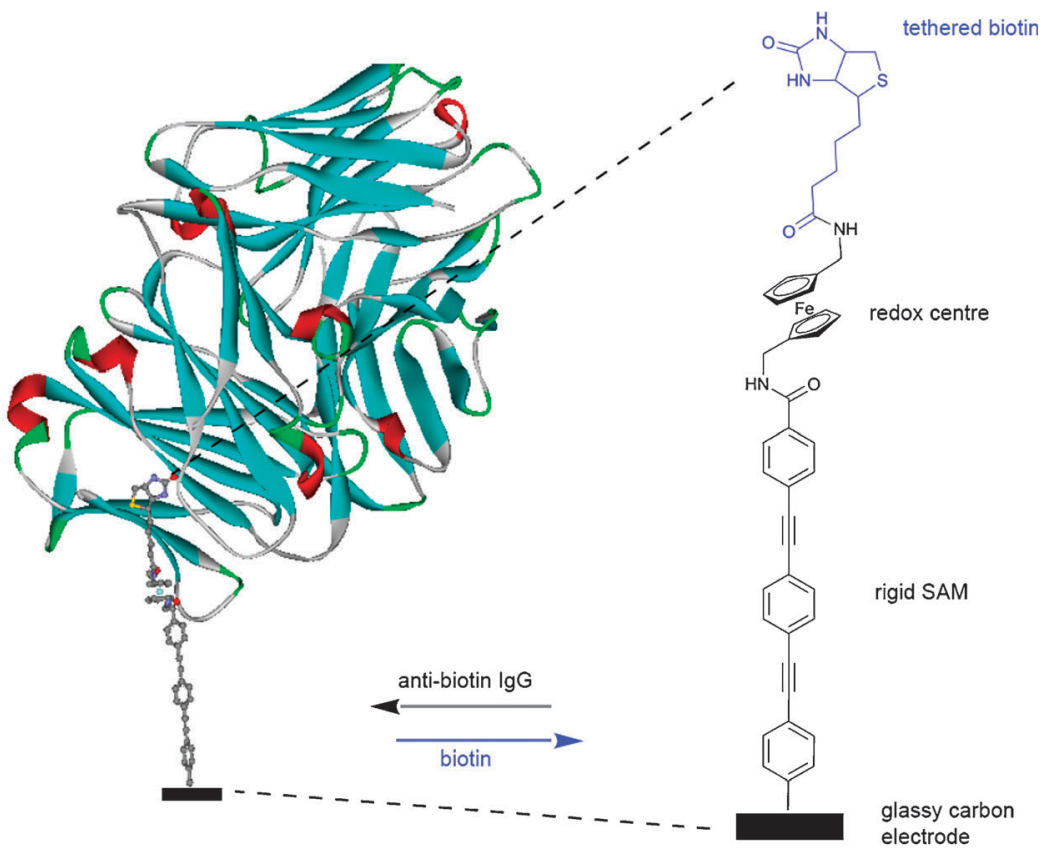

Fig. 1 Highly complex molecular assemblies at a surface. (a) Indium-tin oxide electrodes modified with self-assembled monolayers of porphyrin-fullerene conjugates for photovoltaics applications. (Note: the sacrificial electron donor, triethanolamine, is not shown for clarity) (ref. 14). (b) Modulation of the amperometric signal by antibody/tethered epitope interactions in a label-free immunobiosensor (ref. 15). 
constructs to be formed on a surface will be pre-synthesized versus being formed in a step-wise manner directly off a surface will be covered. Finally, a number of well-established, as well as emerging, coupling chemistry schemes will be outlined prior to finishing with some future perspectives.

\section{Self-assembly systems}

To build molecular scale devices off a surface first requires a means of modifying a surface with molecular level control. The main route to achieving this level of control over surface modification, and the route that has made this field possible, is to use self-assembled monolayers (SAMs). In the broadest sense SAMs are spontaneously formed on a surface when the right conditions are met. In the simplest case, the right conditions may involve placing the surface in a solution of the self-assembling molecule, or in more sophisticated cases monolayer growth may require either illumination, heating or electrode conditioning (i.e. an applied bias). In all cases that will be discussed here, SAM forming molecules include (i) one end that has a high affinity for the surface, (ii) alkyl chains or aromatic rings that play a crucial role in the ordering/packing of the monolayer on the surface, and (iii) a distal moiety which defines the chemical functionality the surface now presents to its environment (Fig. 2). That is, a hydrophobic moiety will make the surface a low energy hydrophobic surface, while hydrophilic, polar, moieties will give a high energy surface.

The reason self-assembled monolayers are attractive for building molecular devices is they can produce layers with well-defined packing and density of specific molecules on a surface and, by incorporating more than one type of molecule into a SAM with molecular scale precision, multifunctional surfaces can be fabricated. Multifunctional surfaces can be produced that, for example, contain components to couple further functionality, components to space coupling points apart, or components to aid in the control of how the surface interacts with its environment (Fig. 1).

Just a few words of caution regarding the depiction of SAM-modified surfaces. Throughout this review, and the majority of the scientific literature on SAMs, the molecular assemblies on surfaces are depicted as cartoons, such as those shown in Fig. 1 and 2. These cartoons have their strengths and weaknesses. Their power is they represent an idealised picture

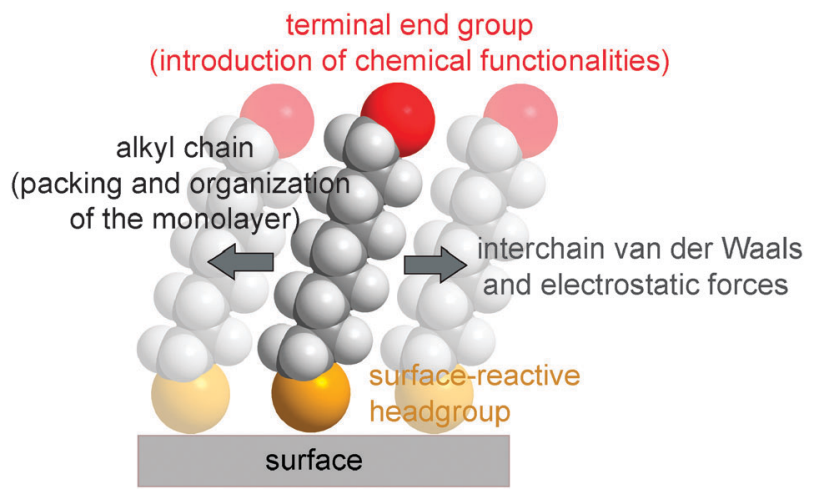

Fig. 2 What does what? Idealized representation of a self-assembled monolayer forming molecule. of what the surface construct might look like. Their flaws are they typically show ordered assemblies on smooth surfaces. Clearly, the surface cannot be completely smooth on the level of individual atoms forming bonds with a surface. This is because the surface atoms have their own shape, and hence cannot form a perfectly flat surface on the atomic level. ${ }^{16}$ Furthermore, any real surface will have defects and domain boundaries that will disrupt the perfect packing of a monolayer. ${ }^{16}$ Similarly, the monolayer forming molecules may not all align on the surface with exactly the same orientation, thus forming domains of slightly different orientation. ${ }^{18,19}$ Finally, inevitably any image shows the monolayer as a static entity but in reality molecules will exhibit their normal fluctuations in position as dictated by thermal motion.

First, some common types of self-assembly systems for surface modification will be discussed. The different systems will be discussed with regards to the types of surfaces they are compatible with and their pros and cons. In principle, all systems we will discuss here will have the potential to form monolayers on a surface, and hence the molecular level control required, but some systems are prone to multilayer formation. That is, we will take a broad view of the definition of a self-assembled monolayer.

\subsection{Organosilane based layers}

Organosilane based monolayers on silicon dioxide and other hydroxylated surfaces are possibly the most commonly exploited self-assembly system. Chemical functionalization of silicon oxide surfaces with silane molecules is an important technique for a variety of device fabrication..$^{20-22}$ One of the main interests is the formation of silanized glass surfaces and their use in non-linear optical devices, ${ }^{23}$ or in sensor applications. $^{24,25}$ In 1980 Sagiv published a seminal paper reporting the reaction of chloro- and alkoxy-silanes $\left(\mathrm{RSiCl}_{3}\right.$ and $\mathrm{RSi}\left(\mathrm{OR}^{\prime}\right)_{3}$ with $\mathrm{R}=\mathrm{C}_{18} \mathrm{H}_{37}$ and $\mathrm{R}^{\prime}=\mathrm{Me}$ or $\mathrm{Et}$ ) with hydroxyl-terminated surfaces of oxidized substrates to afford a covalent molecular layer. ${ }^{26}$ Hydroxyl terminated surfaces include almost any oxide surface such as glass, poly(vinyl alcohol), oxidized polyethylene, aluminium, zinc oxide, iron oxide or indium tin oxide. This work represents the first report of 'ordered molecular assemblies formed by the adsorption of active surfactants on a solid surface', ${ }^{12}$ better known as SAMs. Commonly, the surface is activated prior to the self-assembly in order to clean the surface and maximize the number of silanol groups at the surface. ${ }^{27}$ Alkylsiloxane $(\mathrm{R}-\mathrm{Si}-\mathrm{O}-\mathrm{Si})$ layers are then prepared by a simple self-assembly of the active surfactant, e.g. alkyltrichloro-, alkyltrimethoxy-, or alkyltriethoxysilanes onto the solid substrate. ${ }^{12}$ The properties of these films, i.e. chemical composition, thickness, orientation and lateral order of the alkyl chains have been investigated in detail. $^{28-31}$ As shown by various studies, a precise depiction of the interface between the SAM and the silica is not trivial. A range of factors, including surface hydration and/or water traces in the deposition solution, dictate the precise chemical nature of the interface. A schematic depiction of the proposed silane/silica interface is shown in Fig. 3. It is suggested that only 10 to $20 \%$ of the chains need to form bonds to the surface. The monolayer formation appears thus to be 


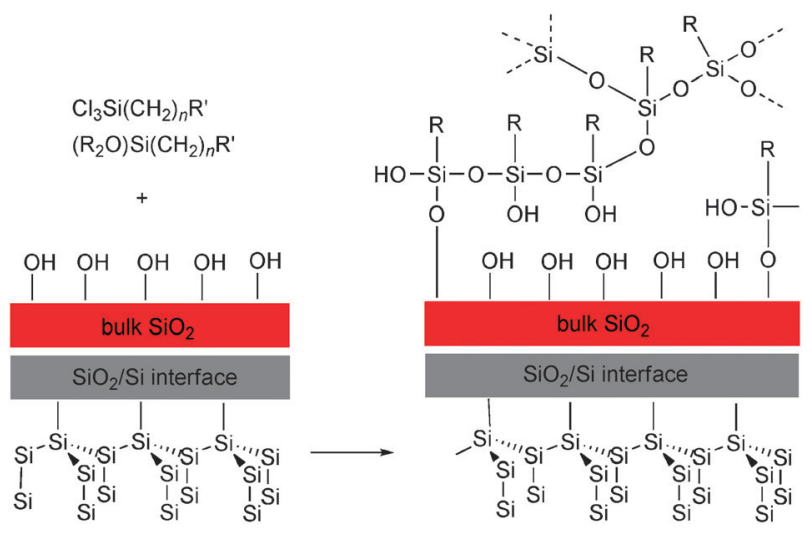

Fig. 3 Interactions between hydrocarbon chains and $\mathrm{Si}-\mathrm{O}$ linkages between adjacent silanols are the driving force in the self-assembly of organosilane systems.

primarily driven by interactions between hydrocarbon chains and $\mathrm{Si}-\mathrm{O}$ linkages between adjacent silanols. We note that the 2D Si-O-Si network between neighbouring silanols shown in Fig. 3 has been greatly simplified for clarity purposes. ${ }^{31}$

There has been considerable debate on the mechanism of chemisorption. ${ }^{32}$ The deposition process is especially complicated; it proceeds through a number of stages, and strongly depends on various parameters, including the solvent and adsorber concentrations, ${ }^{33}$ aging of solutions, water content, ${ }^{34}$ deposition time and temperature. ${ }^{35}$ Initial reports claimed water traces to be essential for the formation of well-packed monolayers. ${ }^{28,36}$ More recent studies showed that with increasing water content, or increasing age of the adsorbate solution, island type growth is strongly favoured. ${ }^{37}$ To further complicate the debate, the film growth seems to proceed by different mechanisms under "dry" or "wet" conditions. ${ }^{34}$ Most importantly, Wang and Lieberman have reported the preparation of ultra smooth octadecyltrichlorosilane (OTS) monolayers by exposing clean native $\mathrm{SiO}_{2}$ surfaces to a dry solution of OTS. ${ }^{34}$ We note that extremely smooth silanized surfaces, i.e. flat at a resolution of few angstroms, have been previously reported. As proposed by Benattar and co-workers in an early report, ${ }^{38}$ the fact that the roughness is low for silanated wafers is also compatible with a vision in which the layer covers the surface without bonding to it, i.e. a film is formed where molecules are linked to each other, and bonded to the surface by only a few bonds. ${ }^{36}$

The simplicity of formation of the $\mathrm{SAMs}$ on $\mathrm{SiO}_{2}$ is a major advantage. However, in common with many of the SAM forming systems, the silanization reaction is relatively easy to carry out, but the formation of a reproducibly well-defined monolayer is exceedingly difficult. ${ }^{31,36}$ Firstly, one of the major issues with this system is the adventitious formation of polycondensed silane (i.e. multilayered products, see Fig. 3), ${ }^{31}$ or physically adsorbed silane molecule on the $\mathrm{SiO}_{2}$ surface. ${ }^{38}$ It is however, very difficult to distinguish physically adsorbed silanes from chemically conjugated SAM molecules. For many applications, whether a monolayer, or rather an ill-defined multilayer is formed, is not a significant issue. On the other hand, when using these systems as the base layer upon which truly molecular devices will be fabricated, ${ }^{22}$ lack of control in the SAM growth can be a major concern. Another challenge with using organosilanes for modifying $\mathrm{SiO}_{2}$ surfaces is the lack of stability in basic media. Thus, for very precise works, the hydrolytic stability of $\mathrm{Si}-\mathrm{O}$ bonds close to the surface may cause performance problems. In summary, some aspects of the organosilane system are far from ideal, but for several substrates (i.e. metal/semiconductor oxides) it just happens to be far and away the best system we have. In fact, $\mathrm{SAMs}$ on $\mathrm{SiO}_{2}$ have provided molecularly defined platforms for numerous chemical derivatization studies and an extensive tool-box of chemical strategies exists now for chemical transformations at the monolayer surface. ${ }^{32}$

\subsection{Alkanethiol and organosulfur self-assembled monolayer}

Organosulfur compounds, and in particular alkanethiols, are the other self-assembled monolayer forming system that dominates the scientific literature. ${ }^{13}$ These molecules spontaneously adsorb onto the surface of gold, silver, platinum and copper. The most frequently used surface is gold because it does not have a stable oxide under ambient conditions, which makes surface preparation simpler. On gold, the thiol groups chemisorb onto the metal to form a gold-thiolate bond; ${ }^{12}$

$$
\mathrm{R}-\mathrm{S}-\mathrm{H}+\mathrm{Au}_{n}^{0} \rightarrow \mathrm{R}-\mathrm{S}^{-} \mathrm{Au}^{+} \cdot \mathrm{Au}_{n}^{0}+1 / 2 \mathrm{H}_{2}
$$

The monolayer formed has the alkyl chains in the all transconformation, tilted $\sim 20-30^{\circ}$ from normal to the metal surface. Once a clean metal surface contacts a solution of alkanethiols a monolayer forms within a few minutes, whereupon there is a slow reorganization over a period of several hours. ${ }^{39}$ The order of the monolayer is derived from the chain-chain interactions. Therefore, any parameter that influences van der Waals interactions between the alkyl chains of the monolayer forming molecules will influence the order of an alkanethiol SAM. SAMs with fewer defects are formed by molecules with longer alkyl chains, ${ }^{40}$ on smoother surfaces, ${ }^{16}$ and with molecules with distal moieties that have a smaller size than the footprint of the alkyl chain $(\sim 20 \AA) .{ }^{39}$

The popularity of alkanethiol SAMs is due to the ease of forming a well-defined monolayer. ${ }^{13}$ As the driving force for formation is the interaction between gold and the thiol, there is no ambiguity as to whether the film is a monolayer or a multilayer system. The real challenge comes in making SAMs which are defect free, or close to defect free.

Mixed monolayers can be produced by having a mixture of alkanethiols in the solution in which the substrate is immersed. The SAMs that result remain as a reasonably homogeneous mixture of the components, especially when the two molecular components have a similar length alkyl chain. ${ }^{41}$ The ability to form homogeneous SAMs from mixtures of alkanethiols is integral to the construction of molecular devices on surfaces.

Surprisingly, the nature of the thiol-gold bond is still subject to controversy, although virtually all applicable characterization techniques have been reported. ${ }^{42}$ The thiol-gold bond is most commonly described as a surface-bound thiolate. The gold-thiolate bond energy is only $170 \mathrm{~kJ} \mathrm{~mol}^{-1}$ due to the polar nature of the bond, causing it to be regarded as a pseudocovalent bond. van der Waals forces between neighbouring molecules stabilize the structure, ${ }^{43}$ but nevertheless alkanethiol 
based SAMs often face stability issues. ${ }^{44,45}$ Typically alkanethiols are stable within a potential window of between +1.0 and $-1.0 \mathrm{~V}$ versus SCE (although this potential window depends on chain length, terminal group and the quality of the underlying gold surface), ${ }^{16,46,47}$ at temperatures below $100{ }^{\circ} \mathrm{C},{ }^{48}$ and seldom for longer than a week or two in air. The poor longterm stability is due to the gold-thiolate bond being prone to oxidation to either sulfinates $\left(-\mathrm{SO}_{2}\right)$ or sulfonates $\left(-\mathrm{SO}_{3}\right){ }^{44,49}$ The rate of photooxidation was found to vary significantly with the alkyl chain length; short-chain length SAMs oxidize much faster than long-chain SAMs. ${ }^{50,51}$ The chemical nature of functionalities at the distal end of the SAM also affects the stability of the system. ${ }^{51}$ We note that experiments by Schoenfisch and Pemberton suggest ozone as the primary oxidant in ambient laboratory air. ${ }^{52}$

The oxidized SAM is far less strongly bound to the gold, ${ }^{53}$ and hence drastically compromises the viability of the final molecular device. The stability over time is particularly an issue when long multi-step fabrication processes are employed, such that the alkanethiol layer has time to oxidize, and with assemblies on nanoparticles, where the high radius of curvature makes it easy for oxygen to reach the gold-thiolate bond. An example is during the synthesis of peptides on an electrode surface ${ }^{54-56}$ or assembling DNA modified surfaces in multiple steps. ${ }^{57,58}$ To address the stability issue some workers have employed organosulfur compounds with two thiols that bond to the gold, ${ }^{56,59-61}$ an approach becoming increasingly popular with molecular assemblies on nanoparticles. ${ }^{62,63}$

Despite alkanethiol SAMs being less stable than desirable, they are the most popular systems for forming molecular assemblies where a molecular level control is required because (i) they provide unprecedented control over the layer formed coupled with the extensive knowledge that has been acquired about these systems, ${ }^{3,13}$ (ii) there are many well established organic synthesis approaches to making complicated molecular structures, ${ }^{64,65}$ (iii) their compatibility with gold means they are ideal for forming molecular assemblies on electrodes, ${ }^{66}$ surface plasmon resonance based optical devices, ${ }^{67}$ and metallic nanoparticles ${ }^{68}$ and (iv) as molecularly smooth gold surfaces can be prepared either from a single crystal, or via template stripping, ${ }^{69}$ molecular devices with highly defined spatial relationships can be prepared.

\subsection{Hydrosilylation reactions at silicon surfaces}

The reaction of 1-alkenes and 1-alkynes at hydride-terminated silicon surfaces is another strategy for forming a selfassembled monolayer. This strategy, known as hydrosilylation, was first reported by Linford et al. and has been the subject of intense interest over the past two decades. ${ }^{70-72}$ The reaction is most commonly initiated using heat or UV/white light (although other approaches are also employed) to create a surface radical which attacks the unsaturated bond to link the alkyl chains to the substrate by a $\mathrm{Si}-\mathrm{C}$ bond. Monolayers grafted in this way are not subject to multilayer formation or hydrolysis (Fig. 4).

The key advantage of this class of monolayer system is that the resultant layer is highly stable because of the nonpolar covalent $\mathrm{Si}-\mathrm{C}$ bond. As there is typically only one coupling point, on most occasions the resultant layer can be guaranteed to be a monolayer. Furthermore, as the underlying silicon surface can be tuned both electronically and topographically this system has incredible versatility. $\mathrm{Si}(111)$ faces can be prepared so that they are molecularly smooth, $\mathrm{Si}(111)$ and $\mathrm{Si}(100)$ can be given both micro and nanoscale roughness, the material can be micromachines and given a variety of structures using classical microfabrication techniques, and can be electrochemically etched to give porous silicon (PSi). The nature of the layer is subtly dependent on the crystal face of silicon due to the different arrangements of silicon atoms on the different faces. However, for most crystal faces approximately one in every two silicon atoms possesses an alkyl chain in a well formed layer and crudely the layers can be regarded as similar. ${ }^{72}$

The disadvantage of this system is however it can prove difficult to achieve good quality layers on silicon without the formation of some oxide. ${ }^{73}$ As any silicon oxide will influence

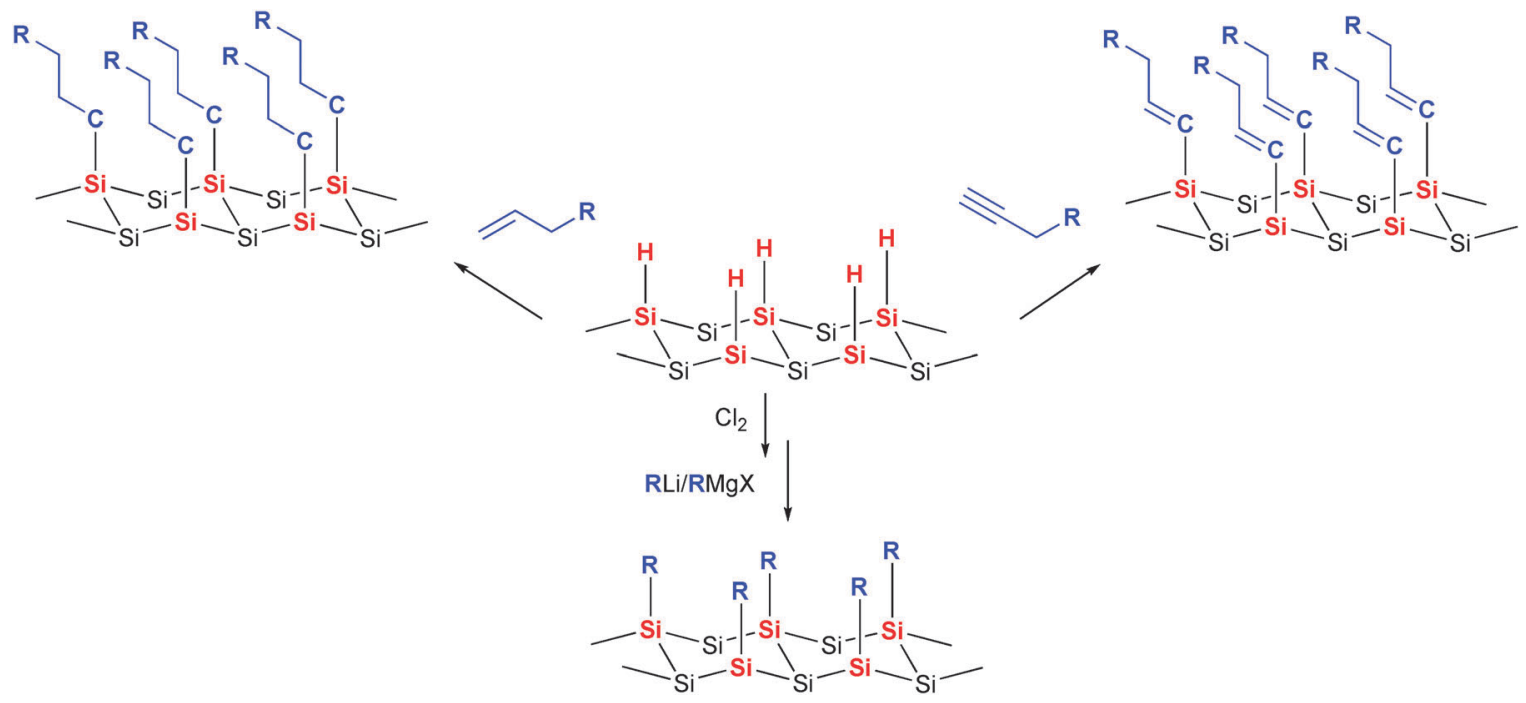

Fig. 4 Hydrosilylation of unsaturated molecules and alkylation of halide-terminated surfaces - wet chemistry routes to silicon-carbon bound monolayers on hydrogen-passivated, non-oxidized, silicon surfaces. 
the electronic properties of molecular devices on planar silicon $^{74}$ and accelerate the degradation of porous silicon in aqueous media, ${ }^{75}$ the challenge is to prepare the layers without any oxidation of the silicon. This requires the surface modification to be performed in an inert atmosphere with degassed chemicals. The difficulty of this challenge is demonstrated by many examples of the literature where visible $\mathrm{SiO}_{x}$ peaks are observed in X-ray photoelectron spectroscopy scans of the Si $2 p$ region of the spectrum.

Further, at present, the chemistry of oxide-free silicon is underdeveloped with respect to that of gold, glass and polymeric surfaces. ${ }^{32,76}$ We remark that as a direct result of the high reactivity of major functional groups (e.g. $-\mathrm{OH},{ }^{77}$ $\left.-\mathrm{C}(\mathrm{O}) \mathrm{H},{ }^{77}-\mathrm{NH}_{2},{ }^{78}-\mathrm{Br},{ }^{79}-\mathrm{C}(\mathrm{O}) \mathrm{Cl},{ }^{80}-\mathrm{SH}\right)^{81}$ toward the $\mathrm{Si}-\mathrm{H}$ surface, means preparation of $\omega$-functionalized monolayers is considerably more difficult than the preparation of simple alkyl monolayers. Notable exceptions are (i) the carboxylic acid functionality $(-\mathrm{C}(\mathrm{O}) \mathrm{OH})$, where only small-to-negligible indications of "upside-down" attachment of the carboxy end of 1-undecylenic acid $\left(\mathrm{H}_{2} \mathrm{C}=\mathrm{C}\left(\mathrm{CH}_{2}\right)_{8} \mathrm{C}(\mathrm{O}) \mathrm{OH}\right)^{82}$ or 10-undecynoic acid $\left(\mathrm{HC} \equiv \mathrm{C}\left(\mathrm{CH}_{2}\right)_{8} \mathrm{C}(\mathrm{O}) \mathrm{OH}\right)^{83}$ have been reported, and (ii) the acid fluoride $(-\mathrm{C}(\mathrm{O}) \mathrm{F})$ group of grafted 10 -undecynoyl fluoride molecules $\left(\mathrm{HC} \equiv \mathrm{C}\left(\mathrm{CH}_{2}\right)_{8} \mathrm{C}(\mathrm{O}) \mathrm{F}\right){ }^{84}$ Nevertheless, hydrogen bonding causes bilayer formation on $-\mathrm{C}(\mathrm{O}) \mathrm{OH}$ SAMs ${ }^{85}$ and further functionalization of the monolayer requires either the preparation of anhydride intermediates, ${ }^{86,87}$ or esterification protocols with $N$-hydroxysuccinimide ( $\mathrm{Si}-\mathrm{RC}(\mathrm{O}) \mathrm{NHS})$, relying on the use of conventional carbodiimide reagents (such as $N$-ethyl- $N^{\prime}$-(3(dimethylamino)propyl)carbodiimide (EDC)). ${ }^{82}$ This last method now represents a widely used platform toward diverse functional silicon surfaces. ${ }^{73,87-95}$

\subsection{Aryl diazonium salt derived layers}

The covalent modification of surfaces with aryl diazonium salts was first described by Pinson and co-workers. ${ }^{96}$ This early example detailed the one-electron reduction of aryl diazonium salts at glassy carbon (GC) surfaces to yield a thin film exposing functionalized aromatic groups. Most importantly, the functionalized aromatic groups decorating the GC electrode surface could be further modified by classical chemical reactions. For example, 4-nitrophenyl groups could be reduced electrochemically to 4-aminophenyl groups. However, it is only recently that aryl diazonium salts have begun to attract a lot of interest for the modification of surfaces with a high degree of control. ${ }^{2}$ The interest is because this one system can be used to modify all allotropes of carbon, ${ }^{97-99}$ gold, platinum and many other metals, ${ }^{100}$ unoxidized silicon, ${ }^{101-103}$ and more recently indium tin oxide. $^{104}$ Furthermore, the electrochemical reduction of a variety of aryl diazonium salts as reported by Tour and co-workers ${ }^{105,106}$ is a viable route for robust modification of small-diameter single-wall carbon nanotubes and has opened possibilities for the preparation of molecular devices. ${ }^{15}$ The aryl diazonium reduction can occur either in aqueous or organic solvents, ${ }^{107}$ and with or without an applied potential. ${ }^{96,108}$ As depicted in Fig. 5, formation of diazoniumbased SAMs is believed to proceed via an aryl radical

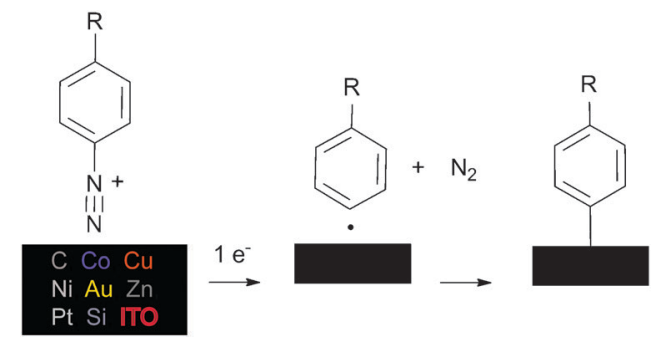

Fig. 5 Functionalization of carbon, metals, metal oxides and semiconductor surfaces by grafting, or electrografting, of aryl diazonium salts.

intermediate, where departure of $\mathrm{N}_{2}$ leaves an unpaired electron, followed by the formation of a covalent bond between the aryl radical and a surface atom of the substrate (aryl radical route). ${ }^{107}$ However, it has been suggested that phenyl groups present at the GC electrode surface may couple with the diazonium species and yield a surface bound azo compound (substituted hydrazine route). ${ }^{107}$ On carbon surfaces the nature of this bond is well understood, but despite XPS evidences supporting the formation of $\mathrm{Fe}-\mathrm{C}$ bonds for diazonium films on iron surfaces, ${ }^{109}$ only limited studies are available for metal surfaces. The resulting covalent layers are highly stable, ${ }^{110}$ in particular with regards to extensive potential cycling during electrochemical measurements. ${ }^{17,111}$ Notably, rigorous comparison studies with well-established self-assembly systems, i.e. SAMs of alkanethiol, have been only performed on gold electrodes. ${ }^{17,111,112}$

It is now generally agreed that depending on the precise experimental conditions used in the self-assembly process (i.e. charge allowed to reduce the diazonium salt, reaction times, concentration of the SAM-forming molecule, nature of the substrate), ${ }^{98}$ further radical attack at the first grafted aryl group can yield a polyphenylene layer (i.e. multilayer system, Fig. 6a), with a thickness up to micrometres. ${ }^{113}$ As depicted in Fig. 6 b, in order to prevent the growth of a polyaryl system, successful approaches include (i) sterically hindering the 3,5-positions, ${ }^{114}$ and (ii) the use of very bulky protecting groups. $^{115}$
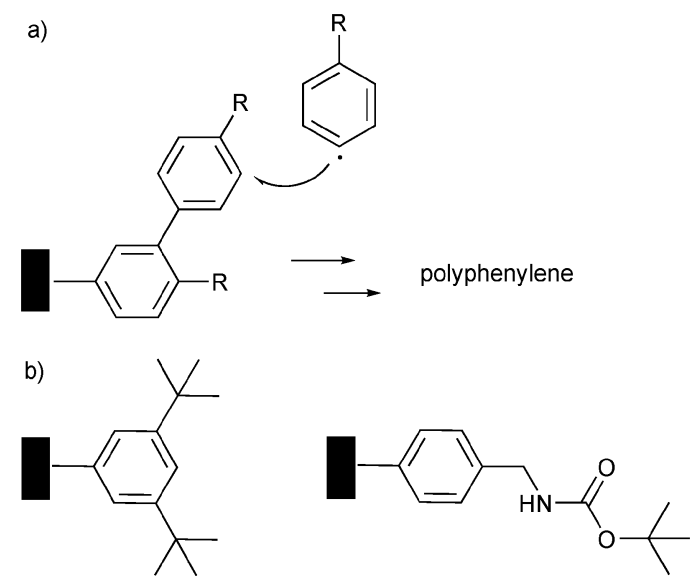

Fig. 6 Possible layer structure resulting from the electrochemical grafting of aryl diazonium salts. (a) Multilayer system due to the attack of an aryl radical on a grafted phenyl group. (b) Prevention of multilayer growth by either hindering the 3- and 5-position or by using bulky protecting groups (ref. 114 and 115). 
Despite the encouraging finding of these recent studies, control is compromised by using aryl diazonium salts but with the benefit of greater stability. ${ }^{116}$ Part of the attraction of aryl diazonium salts, in common with alkanethiols, is that they are reasonably simple to synthesize. A large number of aryl diazonium salt derivatives have been synthesized, ${ }^{97}$ although the literature is still dominated by reasonably simple and commercially available molecules, such as carboxy and nitro derivatives. ${ }^{97}$ The nitro derivative can then be electrochemically converted to the amino species, and hence the two most useful surfaces for the fabrication of biointerfaces, carboxyl and amino terminated surfaces, are readily available. Recently, however, Baranton and Bélanger have greatly broadened the scope of aryl diazonium salt chemistry for surface modification by showing that aniline derivatives can be converted into aryl diazonium salts and deposited onto electrode surfaces in a one step procedure. ${ }^{117}$ This, so-called, in situ generation of an aryl diazonium salt simply required the aniline derivative to be mixed with sodium nitrite in hydrochloric acid. This result implies that any commercially available aniline derivative is now a potential surface-modifying molecule. Furthermore, it has very recently been shown that there is no difference in the ratio of two components in a mixed layer formed using the in situ approach versus using pre-synthesized aryl diazonium salts. $^{118}$

The simultaneous chemisorption of different molecules can provide a high degree of control over the physical and chemical properties of a surface. This has been well demonstrated with alkanethiol molecules on gold surfaces. The formation of mixed layers of aryl diazonium salts on surfaces is however in its infancy. The first example of a multicomponent aryl diazonium salt-derived layer was reported in 2005 by Gooding and co-workers, ${ }^{119}$ and since then some quite sophisticated biointerfaces have been described. ${ }^{15,17,120}$ The formation of mixed layers was achieved by mixing more than one diazonium salt into the solution from which reductive adsorption of aryl derivatives is achieved. The question is how does the ratio of components in solution relate to the ratio of components on the surface? It was recently shown that, as the layer formation is potential assisted, the ratio of components formed on the surface is strongly influenced by the redox potential of each aryl diazonium salt. ${ }^{121}$ That is, from a binary mixture, the species that dominates on the surface is the species which is reduced onto the electrode surface at the more anodic potential. At this point in time however, little more is known about mixed layers derived from aryl diazonium salts, in particular with regards on how the two components are distributed, whether they are forming multilayers, or whether specific associations occur between the different components.

\section{Pre-synthesized versus step-wise fabrication off a surface}

The formation of molecular assemblies on surfaces that contain molecular components with a multitude of different functionalities within that molecule raises a question of how that molecular component should be prepared. The obvious choices are either to synthesize the entire molecule before assembly, or alternatively, to assemble the molecules on the actual surface, one component at a time. We refer to these two approaches as the pre-synthesized and step-wise strategies, respectively. The key question is which is the better strategy? Both strategies persist throughout the literature, but the decisions on which strategy to employ often pertain to the background of the researchers rather than a decision regarding interfacial design. The answer as to whether the pre-synthesized or the step-wise approach is better, depends on the application. Here we discuss two case studies from our own work which, based on the experimental results, come to different conclusions regarding the performances of pre-synthesized versus step-wise assembled molecular devices.

\subsection{Case study 1: ferrocene-modified surfaces for electron transfer studies}

Self-assembled monolayers of alkanethiols on gold surfaces have been used for studying electron transfer processes for many years. ${ }^{10}$ In particular, monolayers in which ferrocene groups are linked to gold electrodes by alkanethiol-based bridges have been studied in great detail. The ferrocene moiety is typically diluted on the surface using, most frequently, an alcohol-terminated species. ${ }^{65,122}$ These surfaces have been prepared either by assembling a mixed SAM of the presynthesized ferrocene derivative with an appropriate diluent molecule, ${ }^{123-125}$ or by assembling a mixed SAM composed of the diluent and a carboxylic acid derivative molecule, followed by attaching ferrocene methyl amine, ${ }^{122}$ or similar redox nucleophilic derivatives, ${ }^{90,126}$ onto the carboxyl termini. Cyclic voltammetry is a common means to determine the electron transfer kinetics and to evaluate the quality of the prepared interface for electron transfer studies. A good marker of the quality of such monolayers is the width at half maximum of the oxidation and reduction waves in cyclic voltammograms $(\mathrm{CVs}), \Delta E_{\mathrm{fwhm}}$. In the ideal case, i.e. when the interface is well prepared and with non-interacting ferrocenyl units experiencing the same environment, $\Delta E_{\mathrm{fwhm}}$ will be $90.6 / n$ at room temperature (where $n$ refers to the number of electrons transferred in the electrochemical reaction). Fig. 7 shows representative $\mathrm{CV}$ s for interfaces formed either in a step-wise manner or from pre-synthesized molecules. In the former case of a surface prepared stepwise (Fig. 7a), measured CVs show very broad and asymmetrical peaks $\left(\Delta E_{\mathrm{fwhm}}=c a .170 \mathrm{mV}\right)$ indicating that the ferrocene derivatives are in a multitude of environments. Such an interface is inappropriate for high quality electron transfer studies. In contrast, the interface prepared from the pre-synthesized molecule (Fig. 7b) gives a $\Delta E_{\mathrm{fwhm}}$ value between 95 and $100 \mathrm{mV}$, which is very close to ideal, and may then provide robust electron transfer information. ${ }^{65,127}$ The difference in performance of these two interfaces clearly shows the advantages of the pre-synthesized approach, which gave far greater certainty over the composition and organization of the electrode interface.

\subsection{Case study 2: modification of porous silicon}

Porous silicon (PSi) photonic crystals hold considerable promise as sensors for in vivo monitoring. ${ }^{128}$ This is partly because they provide a label-free sensing device from a material that is (i) biocompatible, (ii) degrades in the body 

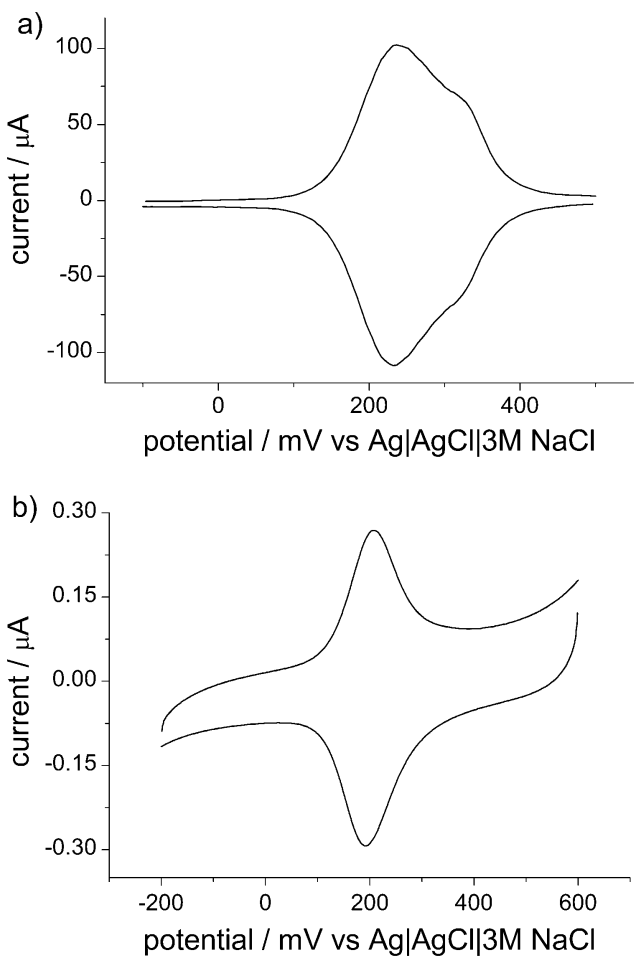

Fig. 7 Step-wise (a) versus pre-synthesized (b) fabrication of redox-active SAMs for electron transfer studies.

to benign products, and (iii) can be designed such that the reflectivity spectra are tuned to the so-called 'tissue window' (near infrared), where there is significant light penetration through the skin, such that implanted devices can be monitored optically from outside the body. To make these optical PSi structures into selective sensing devices, however, requires surface modification of the inorganic PSi structure using either silane chemistry, ${ }^{129}$ if the silicon is oxidized, or hydrosilylation chemistry if "as prepared" (i.e. hydrogenterminated) structures are employed. ${ }^{130}$ Surface chemistry modification is required to address three tasks. ${ }^{130}$ First is to protect the underlying silicon from the ingress of water and oxygenated species that cause the PSi to oxidise and dissolve in physiological media. The second is to render the surface resistant to non-specific protein adsorption. The third is to provide coupling points to which biological recognition species such as DNA, antibodies or enzymes could be attached. Representative molecules we have designed to perform these tasks are shown in Fig. 8. We initially attempted to incorporate all three components in a pre-synthesized molecule, however, such interface was unable to provide adequate protection against silicon oxidation, with the device being completely degraded in biological solutions within two days. ${ }^{73}$ However, forming the interface in a stepwise manner with first grafting a base alkyl layer, followed by the attachment of the anti-fouling moieties and by activation of terminal groups to allow biology to be attached, gave a totally different result. In the stepwise case the structures were shown to be detectable in biological media for up to 60 days with no evidence of any oxidation of silicon within the first 4 days. ${ }^{73}$ The ability to stabilise PSi structures was vital for subsequent a)<smiles>[R]NC(=O)OCC</smiles><smiles>[R]NCC(O)C(C)CCCCC(C)C(O)CS[R]</smiles>

c)

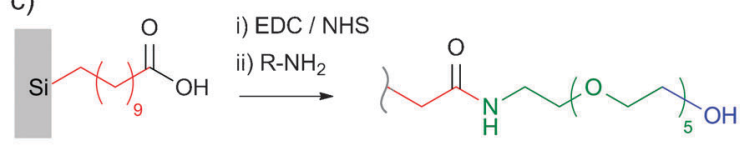

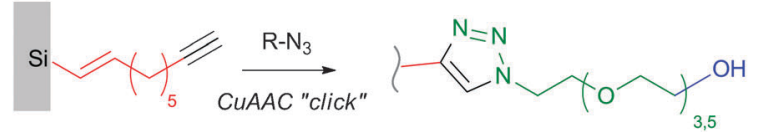

Fig. 8 Alternative chemical strategies for the derivatization of PSi for sensing applications. The alkyl portion of the layer (red) serves to stabilize the device against oxidation, limited non-specific adsorption of proteins is ensured by an anti-fouling component (green), and reactive termini (blue) are used for further SAM derivatization. (a and b) Pre-synthesized approach toward robust, anti-fouling and chemically versatile (i.e. derivatizable) SAMs. (c) Step-wise fabrication using either carbodiimide- or CuAAC-based approaches.

applications, where the photonic crystals were modified with peptides and used to detect the release of proteolytic enzymes from living cells. ${ }^{131}$

The poor performance of the pre-synthesized molecule in the case of PSi photonic crystals was attributed to the oligo(ethylene oxide) moieties being highly flexible, and thus disrupting the packing of the SAM.

\subsection{What do we learn from the case studies?}

The two case studies discussed above show clearly that whether using pre-synthesized molecules, or instead opting for a step-wise formation of molecular layers, is entirely dependent on the function of the interface.

The clear advantage of the pre-synthesized approach is that surface modifying molecules can be purified prior to assembly, and hence greater certainty over the composition of the interface is expected. This was evident with the examples of case study 1 (Section 3.1), where subtle changes in environment 
around ferrocenyl molecules markedly influenced the electrode performance. With the step-wise synthesis of ferrocenemodified electrodes, the quality of the redox interface is defined by the coupling efficiency between the base monolayer and the ferrocene derivative. As such surface reactions are seldom quantitative, there is inevitably a mixture of species on the surface and physical adsorption of ferrocene derivatives onto the surface is also expected. Hence, the ability to purify the SAM-forming molecules prior to assembly is part of the reason for the superior redox response found with the pre-synthesized ferrocene derivative.

A perceived disadvantage of the pre-synthesized approach is in that it requires the experimentalist to synthesize a new molecule for every single interface to be explored. In the case of the ferrocene interface prepared via the step-wise approach, SAM-forming species are commercially available, and hence accessible to researchers without particular synthetic skills. We, however, do not regard synthetic expertise as an important criterion by which the decision of how to make a sophisticated interface is made, and advocate that, when possible, the pre-synthesized approach is a better approach to take.

However, case study 2 (Section 3.2) illustrates an example where a step-wise approach to a multicomponent interface can in fact be a superior strategy. That is, when some of the moieties within an interface forming molecule are too bulky to allow for the effective formation of the interface. The even more common reason is incompatibilities of different molecular components. For example, in the device for protein electrochemistry of Fig. 1 the interface, comprised of the oligo(ethylene oxide) spacer molecules (not shown) and the "molecular wire" (i.e. phenylethynyl bridge), is assembled in acetonitrile, which is a solvent in which the proteins employed would denature. Hence there is no choice but to form the interface in a step-wise manner. Besides solvent incompatibilities, there is also the possibility that the conditions in which the self-assembly occurs in may not be compatible with some of the molecular components involved. This is for example the case with the methods we use to perform hydrosilylation chemistry, where either high temperatures or UV illumination are employed, both of which could denature biological molecules.

In the cases when the step-wise approach is required, the quality of the final interface will be determined at a large extent by the efficiency and selectivity of the coupling chemistry involved.

\section{Selected coupling chemistries and their relative virtues}

As the discussion above indicates, we favour synthesizing the entire molecular construct in solution prior to assembly on a surface but there are many surface constructs, for many different reasons, where that is just not possible and a stepwise approach is the only way to fabricate the required functionality on a surface. If a step-wise approach is the only way forward, then the logical question is, "what functional groups would be best to have on the distal end of the base layer?". Again, the answer to such a question depends on what the layer is required to do. Much of the early science in understanding monolayer constructs on surfaces concentrated on methyl terminated monolayers. The reasons for this are both scientific and practical. From a scientific perspective, the methyl group typically having limited affinity for the underlying substrate and hence the surface binding mode of the active surfactants was unambiguous. Practically, the broad range of commercially available SAM-forming molecules allowed detailed studies as a function of molecular length to be easily performed. Nevertheless, the covalent modification of the poorly reactive alkyl termini suffers from low yields (ca. $10 \%$ ) and has seen very limited use. ${ }^{132}$ As a consequence, a wealth of chemical strategies has been developed for the derivatization of $\omega$-functionalized SAMs. In the following sections we discuss both some recent developments, and established platforms, for the step-wise modification of a surface.

\subsection{Carbodiimide-based approaches}

It is almost undeniable that the most common coupling strategy involves the linking of carboxylic acid with amines to form an amide bond. Within this context, carbodiimides reign supreme at least in popularity. The popularity of this approach comes from its compatibility with biology and its simplicity. Carbodiimide reagents (e.g. $N, N^{\prime}$-dicyclohexylcarbodiimide (DCC) or $N$-ethyl- $N^{\prime}$-(3-(dimethylamino)propyl)carbodiimide (EDC) $)^{133}$ are now a routine laboratory tool in the field of self-assembly. ${ }^{72,134,135}$ Both DCC and EDC are commercially available reagents, and can be used in either organic solvents (DCC) or aqueous solutions (EDC). In the simplest case, a carboxylic acid terminated surface is immersed in a solution of the appropriate carbodiimide reagent, yielding a reactive $O$-acylurea intermediate (Fig. 9). This reactive ester intermediate is susceptible to nucleophilic attack by amines, and can be therefore directly converted into the intended amide product. Nevertheless, when this reaction is carried out in an aqueous environment, with a water-soluble carbodiimide, the activated $O$-acylurea intermediate is subject to hydrolysis. This hydrolysis can severely limit conversion rates. ${ }^{136}$ Typically, in aqueous solution $N$-hydroxysuccinimide (NHS) is included to assist the EDC-mediated amidation reaction. ${ }^{133}$ NHS displaces the carbodiimide active ester (i.e. the $O$-acylurea intermediate) to give a succinimide ester (Fig. 9). NHS esters are still reactive toward attack by amine nucleophiles and remarkably less prone to hydrolysis than the parent carbodiimide ester. In solution phase, product yields as high as $90 \%$ can be routinely achieved. ${ }^{136} \mathrm{~A}$ first consequence of the greater coupling yields is that many succinimide ester terminated SAM forming molecules are also commercially available. ${ }^{136}$ Importantly, in the contest of carbodiimide chemistry at a surface, NHS esters have a small footprint, and hence more of the surface carboxyls are activated. ${ }^{137}$ Apart from amines, NHS activated films are open to the immobilization of substituted hydrazine $(-\mathrm{CO}-\mathrm{NH}-\mathrm{NH}-\mathrm{R})^{94}$ and alcohols. This two-step procedure (activation followed by nucleophilic displacement) does not require harsh hydrolysis steps as in the case of tethered acid esters, which is why it is so compatible with biological molecules. It is also worth noting 


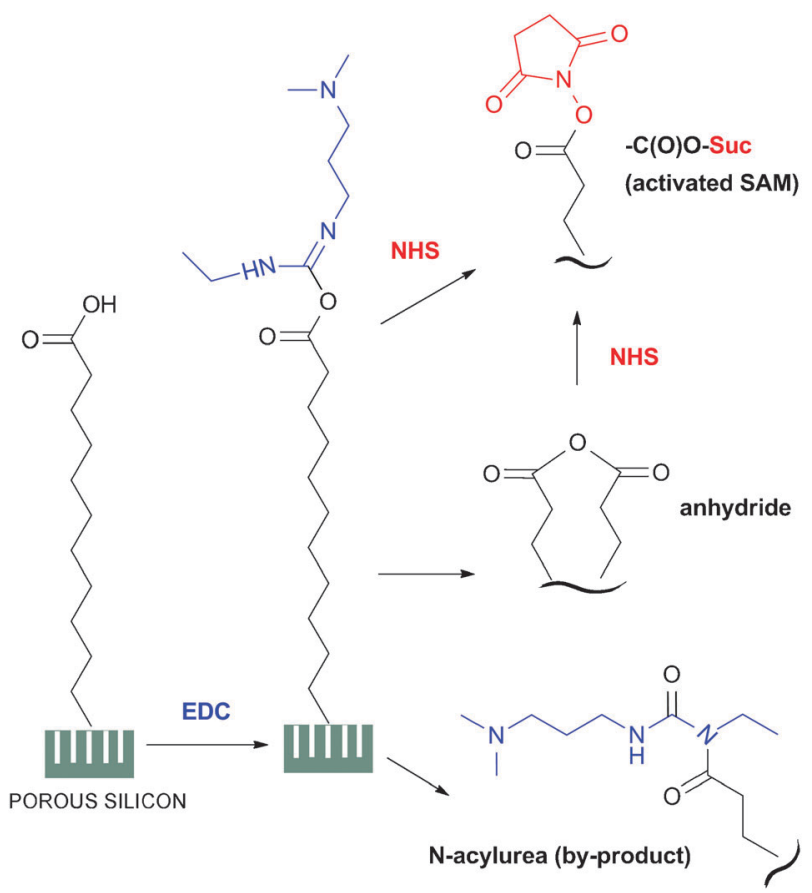

Fig. 9 NHS-assisted activation of $\mathrm{COOH}$ termini via carbodiimide (EDC) reagents. Concurrent alternative reaction pathways are shown (ref. 87).

that an optimization study to evaluate the optimal range of NHS and EDC concentrations and molar ratios has only very recently been published for silicon substrates by Sam et al. ${ }^{87}$ The authors have systematically varied the concentrations of the two reagents, and semiquantitatively evaluated, via transmission FTIR spectroscopy, the presence of unreacted $O$-acylurea and anhydride species, as well as the relative abundance of by-products (e.g. $N$-acylurea) and desired reaction product. Very high yields (i.e. close to $100 \%$ ) for the activation reaction were found for a restricted range of NHS and EDC concentrations and molar ratios $(5 \mathrm{mM}<$ $[\mathrm{EDC}] \approx[\mathrm{NHS}])$. This was explained in terms of kinetic competition between different reaction pathways (Fig. 9). Despite the high coupling yields reported by Sam et al., more typical coupling yields are around $50 \%$ for many surface coupling reactions.

The method presents some limitations with regards to sterically hindered molecules (e.g. single-strand DNA oligomers tethered to a primary amine linker). Furthermore, it is important, although often forgotten, to use a small capping agent, such as ethanolamine, to deactivate unreacted sites. $^{88,138}$ Another point of caution relates to the surface coupling of proteins using carbodiimide reagents. The experimentalist could modify the surface with a carboxylic acid terminated SAM, activate the carboxyl using EDC/NHS, and subsequently couple the protein to the NHS-activated SAM (i.e. two-step procedure). Alternatively, a protein of interest can be coupled onto an amine-terminated surface in the presence of both EDC and NHS (i.e. one-pot procedure). Naively, these two alternatives (two-step versus one-pot) may be thought to deliver the same basic product but this could not be further from the truth. In the latter case with an amine terminated SAM, the protein and the EDC/NHS coexist in solution, which means free amines on the protein, as well as the surface amines, can nucleophilically attach the active esters on the protein, causing the protein to crosslink. Hence a monolayer of protein is not achieved. With the activation of a carboxyl terminated SAM, the surface can be removed from the EDC/NHS solution after activation, and subsequently be placed in a protein solution free of activating agents. In this way a monolayer of protein can be guaranteed (provided the protein does not aggregate to itself).

\subsection{Maleimide-derivatized surfaces}

Toward the preparation of reactive SAM surfaces for protein and oligonucleotide binding, several amine- and thioltagged precursors have been investigated. Examples include (3-mercaptopropyl)trimethoxysilane (MPS) and (3-aminopropyl)trimethoxysilane (3-APS) on silica surfaces. On nonoxidized silicon surfaces, however, protection and deprotection of the amine group is required. ${ }^{139}$ The great majority of these SAM-forming molecules are commercially available, so that SAM deposition procedures involve no, or minimal, synthetic effort. ${ }^{140}$ Linking of biomolecules onto amino-termini can be accomplished in a three-step procedure using heterobifunctional reagents (e.g. $N$-succinimidyl 6-maleimidocaproate (EMCS), Fig. 10). Free amino groups on the surface serve as anchoring points to which the succinimide groups of the crosslinker EMCS are covalently attached through amide bonds. The resulting pendant maleimide residue of EMCS can in turn be used in Michael addition reactions with thiolated molecules, for example cysteine residues, yielding a covalent thioether linkage. ${ }^{141}$ Moreover, maleimide-derivatized glass slides provide an excellent synthetic route to immobilized proteins due to their inherent stability and specificity to thiols, ${ }^{142}$ and due to the resistance to nonspecific adsorption. Further examples of maleimide-based strategies for the functionalization of SAMs include the attachment of thiolated oligonucleotides onto APS films by using $N$-succinimidyl 4 -( $p$-maleimidophenyl)butyrate (SMPB), ${ }^{24}$ or the attachment of an antibody onto 3-mercaptomethyldimethylethoxysilane (MDS) monolayers by using various amine-reactive heterobifunctional linker molecules differing from each other by their thiol-reactive site (e.g. SMPB, $N$ - $(\gamma$-maleimidobutyryloxy) succinimide ester (GMBS), $N$-succinimidyl-3-(2-pyridyldithio)propionate (SPDP), $N$-succinimidyl-(4-iodoacetyl)aminobenzoate (SIAB) (Fig. 10)). ${ }^{143}$

\section{3 "Click" reactions between azides and alkynes}

An emerging coupling procedure by which further functionality can be added to a surface is via the copper(I)-catalyzed alkyne-azide cycloaddition (CuAAC) "click" reactions. ${ }^{144-147}$ $\mathrm{CuAAC}$ reactions benefit from high selectivity, modularity, the absence of both activation and protection/de-protection steps, and are tolerant to a wide range of solvents and functional groups. ${ }^{146,148}$ Notably, the azido and ethynyl functional groups are not common in nature. The advantage of this is there will be no ill-defined covalent attachment of biomolecules to a surface using "click" chemistry protocols. On the other hand, a disadvantage is that biomolecules will require modification prior to coupling using this chemistry 


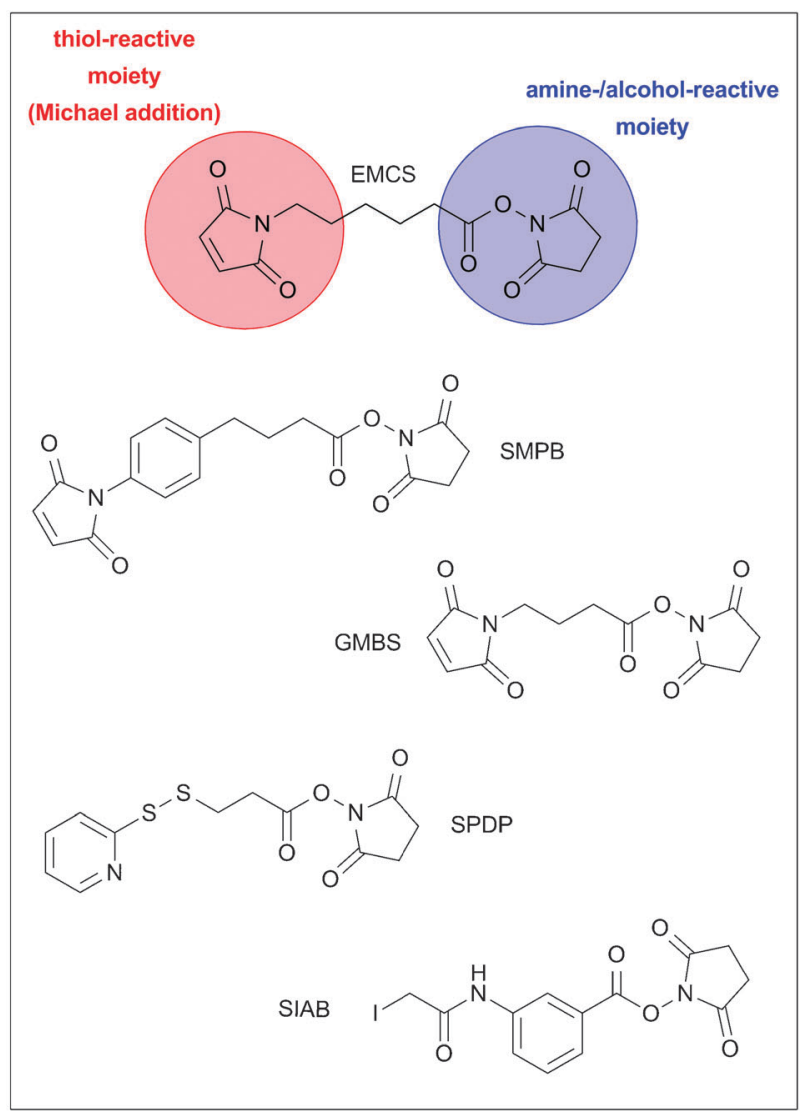

representative heterobifunctional crosslinker molecules<smiles>CO[Si](C)(C)CS</smiles><smiles>CO[Si](C)(C)OC1CC(=O)N(CCCC(=O)ON2C(=O)CCC2=O)C1=O</smiles>

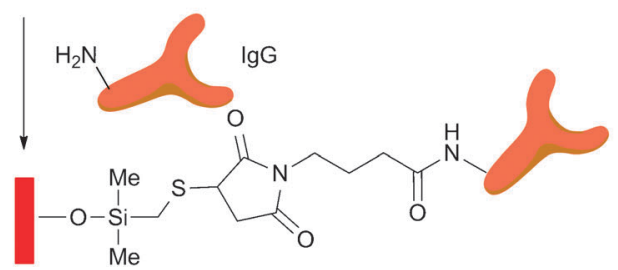

Fig. 10 Examples of commercially available thiol- and amine-/hydroxylreactive heterobifunctional crosslinker molecules. The immobilization of IgG molecules onto thiol-terminated SAMs is an early example of a straightforward protocol toward functional antibody molecules immobilized on glass cover slips (ref. 143).

(i.e. azide- or alkyne-tagging). The excitement generated by this class of chemistry for surface modification may be traced back to a report from Chidsey and co-workers in which was claimed quantitative (for coverages lower than the steric limit) coupling between a surface azide and a solution alkyne species. ${ }^{149,150}$ Remarkably, when an alkyne-tagged ferrocene derivative was "clicked" onto an azide-modified gold electrode, cyclic voltammograms with $\Delta E_{\text {fwhm }}$ values close to $90.6 / n$ were observed. That is, as referred to in case study 1 (Section 3.1), this chemistry allowed the stepwise fabrication of a redox interface with nearly ideal electrochemical behaviour. This example shows the virtues of this "click" reaction-the absence of side reactions and high conversion rates.

Since this work there has been an explosion of interest into "click" chemistry on surfaces. ${ }^{76,147}$ Examples of species that have been coupled to surfaces in this way include, oligo(ethylene oxides) to render surfaces protein resistant, ${ }^{151}$ peptides, ${ }^{152}$ DNA strands, ${ }^{153}$ carbohydrates, ${ }^{154}$ porphyrins ${ }^{155}$ and quinones. ${ }^{156}$ Of these many studies, one by our group illustrates an additional advantage of this class of chemistry. We modified hydrogen terminated $\mathrm{Si}(100)$ surfaces with an $\alpha, \omega$-dialkyne (1,8-nonadiyne) via a hydrosilylation reaction. ${ }^{157}$ The distal alkyne was then used to couple a variety of different azido species, including an azido ferrocene derivative, ${ }^{158,159}$ to the distal end of the SAM. In common with the Chidsey work, the $\Delta E_{\text {fwhm }}$ was close to ideal for the surface bound ferrocene. ${ }^{159}$ However, what was particularly surprising was that these modified surfaces could be scanned anodically in aqueous solution for 200 or more redox cycles with no apparent oxidation of the underlying silicon. Such protection of silicon from oxidation is unprecedented. The studies showed that if the surface dialkyne was diluted with a monoalkyne (1-heptyne), such that there was not a distal alkyne, this protection against oxidation gradually diminished. It was hypothesised that the affinity of the distal alkynes to each other via $\pi-\pi$ bonding, and then subsequently the distal triazole rings once coupling occurred, gave the surface the much greater protection from oxidation. If this hypothesis is correct it points to an important lesson. In most cases with $\omega$-functionalized SAMs the distal moieties are reasonably polar, or charged, and repel each other. We suggest that greater surface stability would be achieved with SAMs where there was strong affinity between the molecules at the distal end. Previous work on phenyl based alkanethiols has shown that as well.

\subsection{Diels-Alder reactions}

Another emerging class of coupling chemistry for surface modification is the Diels-Alder cycloaddition. In a traditional Diels-Alder reaction a diene is attacked by a dieneophile, resulting in a ring structure. The advantage of the Diels-Alder approach is that it is a highly chemoselective bioconjugation strategy, in that it involves a diene and a dienophile not found in any biological molecule. No protection schemes are therefore required, and the reaction is also fast and efficient in aqueous media. Diels-Alder reactions have been used for the immobilization of diene- and maleimide-functionalized oligonucleotides, ${ }^{160}$ carbohydrates, ${ }^{161}$ and peptides ${ }^{162}$ on gold and glass surfaces. In a very elegant work, Chaikof and co-workers have prepared complex interfaces using sequential Diels-Alder cycloaddition and CuAAC reactions (Fig. 11). ${ }^{154}$ Maleimidederivatized glass slides (the dienophile) were functionalized with diverse ligands, including biotin, lactose, and a recombinant S-tagged thrombomodulin protein. As complete conversion 


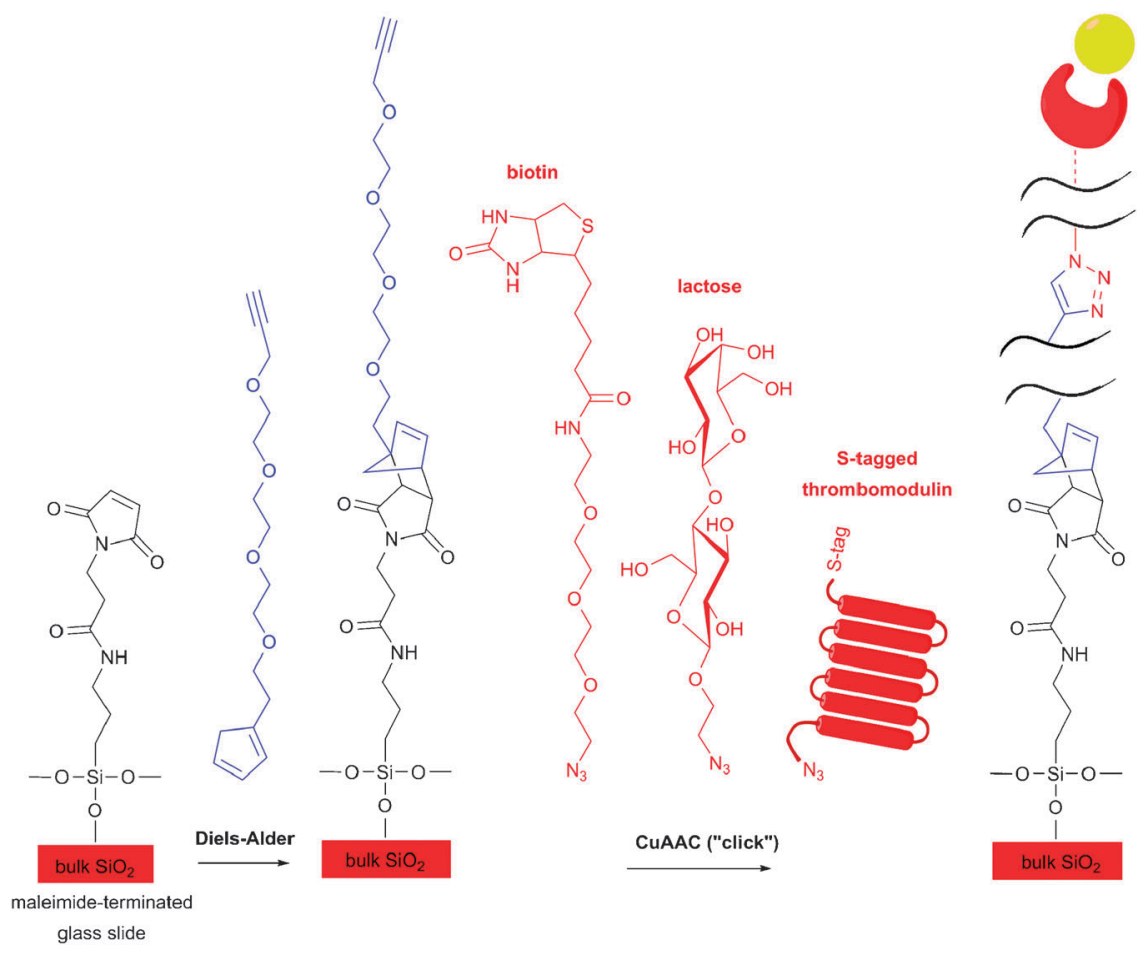

Fig. 11 Tandem Diels-Alder and "click" CuAAC reactions to derivatize anti-fouling silica surfaces with azide-tagged biomolecules (ref. 154).

was not achieved via Diels-Alder reactions, unreacted maleimide groups were blocked by incubation in a solution of cysteine. More recently reversible Diels-Alder chemistry has been used to manipulate surface wettability of the silanized glass surfaces. ${ }^{163}$ The relationship between the rate of an interfacial Diels-Alder reaction and the steric congestion around the reacting molecules has been studied in detail. ${ }^{164}$ It was found that for monolayers presenting quinone groups (the dienophile) in an accessible environment, i.e. when using short hydroxyl-terminated diluents molecules, reaction rates were approximately seven-fold faster than those for monolayers with the quinone group buried within the SAM.

\subsection{Acetylenic coupling}

Quite surprisingly, despite the wide and diverse use of acetylene "building blocks" in solution-phase chemistry, ${ }^{165}$ there are few published studies, apart from $\mathrm{CuAAC}$ reactions, that have reported on the unique properties of the carbon-carbon triple bond in the context of derivatizing solid substrates. We predict alkyne-alkyne coupling will become increasingly popular. Notable examples include (i) the preparation of 1-ethynylpyrene-modified oligonucleotides using Sonogashiratype cross-coupling conditions on controlled pore glasses, ${ }^{166}$ (ii) Cadiot-Chodkiewicz coupling of (triisopropylsilyl)protected bromoacetylene and alkyne-terminated selfassembled monolayers of alkanethiolate on gold, ${ }^{167}$ (iii) the work of Bedzyk and co-workers detailing the use of microwave-assisted Sonogashira reactions, ${ }^{168}$ and more recently (iv) the report by Gooding and co-workers on the Hay catalytic system [ $\mathrm{CuCl}, N, N, N^{\prime}, N^{\prime}$-tetramethylethylenediamine] under non-stringent oxidative conditions to bridge ferrocenyl units to passivating alkenyl $\mathrm{Si}(100)$ monolayers through a 1,3-diyne $(-\mathrm{C} \equiv \mathrm{C}-\mathrm{C} \equiv \mathrm{C}-)$ linker. ${ }^{169}$

\section{Summary and perspectives}

The modification of surfaces with molecular constructs has made incredible advances in the last 15 years or so. The level of sophistication that has been achieved is incredible, with some surface-modifying layers containing over 10 different molecular components. Surface tethered molecular components can serve a multitude of scopes, including coupling biomolecules, allowing electron transfer through layers, blocking access of proteins and other species to surfaces, orientating other molecular components on a surface and capturing light or electrons. What this high degree of control at the molecular level has provided is not only access to better performing surfaces but an entirely new way of doing things such as sensing, converting light to energy, or switching materials properties. Molecular level approaches to modifying surfaces are in some ways the essence of molecular nanotechnology, and therefore promises to become even more popular and an even more developed field in the future.

The aim of this critical review is to highlight, to researchers interested in the fabrication of surface molecular constructs, some of the issues that they may face, some of the decisions that may need to be made, and to outline some of the lessons we have learnt in our experience in modifying surfaces. Saying that, this review really only gives one half of the story with regards to molecular nanotechnology. The half of the story that has been given is how to go about fabricating the molecular construct on a surface. Hence the tone has been forward looking, attempting not to inform the reader as to 
what has been done but more to emphasize how to do things. The other half of the story however is "how do you know whether you have made what you intended to make'? In our own research, it is the characterisation of molecular constructs on surfaces that takes as much, if not more time, than actually working out how to fabricate the device. We typically use a suite of techniques such as X-ray photoelectron spectroscopy, electrochemistry, surface spectroscopy, X-ray reflectometry and scanning probe microscopy, but there are a plethora of other techniques also available. However, the application of such techniques to the characterisation of modified surfaces has been extensively reviewed, whereas, we felt, the strategies for making complicated molecular constructs on surfaces warranted further discussion.

Although this account is biased by our own experience, we feel it provides a good starting point in how to modify surfaces with multiple functionalities with a high degree of control. The messages are: (i) consider the surface that is built upon from the perspective of its topography, structure and the chemistry; (ii) with that knowledge make a choice on the modifying chemistry, keeping in mind the level of control achieved, the stability of the modifying layer and how easily the modification chemistry can be achieved; (iii) decide whether a pre-synthesized molecular construct will be used to modify the surface or a step-wise strategy will be employed based on the compatibility of the molecular components with the self-assembly conditions and whether a high quality layer, with sufficient control of the molecular packing, can be achieved using the presynthesized approach; and finally, (iv) characterise, characterise and characterise to really prove the molecular construct has been prepared as intended (that is, as the cartoons suggest). Good luck.

\section{Acknowledgements}

The authors thank the Australian Research Council (project number DP1094564) for support.

\section{Notes and references}

1 M. C. Hersam, N. P. Guisinger and J. W. Lyding, Nanotechnology, 2000, 11, 70-76.

2 J. J. Gooding, Electroanalysis, 2008, 20, 573-582.

3 J. J. Gooding, F. Mearns, W. Yang and J. Liu, Electroanalysis, $2003,15,81-96$

4 A. Vilan, O. Yaffe, A. Biller, A. Salomon, A. Kahn and D. Cahen, Adv. Mater., 2010, 22, 140-159.

5 R. Har-Lavan, I. Ron, F. Thieblemont and D. Cahen, Appl. Phys. Lett., 2009, 94, 043308.

6 I. Willner, Science, 2002, 298, 2407-2408.

7 K. L. Prime and G. M. Whitesides, J. Am. Chem. Soc., 1993, 115, 10714-10721.

8 R. L. McCreery, Chem. Mater., 2004, 16, 4477-4496.

9 A. H. Flood, R. J. A. Ramirez, W.-Q. Deng, R. P. Muller, W. A. Goddard III and J. F. Stoddart, Aust. J. Chem., 2004, 57, 301-322.

10 D. M. Adams, L. Brus, C. E. D. Chidsey, S. Creager, C. Creutz, C. R. Kagan, P. V. Kamat, M. Lieberman, S. Lindsay, R. A. Marcus, R. M. Metzger, M. E. Michel-Beyerle, J. R. Miller, M. D. Newton, D. R. Rolison, O. Sankey, K. S. Schanze, J. Yardley and X. Zhu, J. Phys. Chem. B, 2003, 107, 6668-6697.

11 V. Chechik, R. M. Crooks and C. J. M. Stirling, Adv. Mater., 2000, 12, 1161-1171.
12 A. Ulman, Chem. Rev., 1996, 96, 1533-1554.

13 J. C. Love, L. A. Estroff, J. K. Kriebel, R. G. Nuzzo and G. M. Whitesides, Chem. Rev., 2005, 105, 1103-1170.

14 H. Yamada, H. Imahori, Y. Nishimura, I. Yamazaki, T. K. Ahn, S. K. Kim, D. Kim and S. Fukuzumi, J. Am. Chem. Soc., 2003, 125, 9129-9139.

15 G. Liu, M. N. Paddon-Row and J. J. Gooding, Chem. Commun., 2008, 3870-3872.

16 D. Losic, J. J. Gooding, J. G. Shapter, D. B. Hibbert and K. Short, Electroanalysis, 2001, 13, 1385-1393.

17 G. Liu, T. Böcking and J. J. Gooding, J. Electroanal. Chem., 2007, 600, 335-344.

18 G. E. Poirier, Chem. Rev., 1997, 97, 1117-1128.

19 M. J. Giz, B. Duong and N. J. Tao, J. Electroanal. Chem., 1999, $465,72-79$.

20 M. Halik, H. Klauk, U. Zschieschang, G. Schmid, C. Dehm, M. Schutz, S. Maisch, F. Effenberger, M. Brunnbauer and F. Stellacci, Nature, 2004, 431, 963-966.

21 S. Kobayashi, T. Nishikawa, T. Takenobu, S. Mori, T. Shimoda, T. Mitani, H. Shimotani, N. Yoshimoto, S. Ogawa and Y. Iwasa, Nat. Mater., 2004, 3, 317-322.

22 Q. Li, G. Mathur, S. Gowda, S. Surthi, Q. Zhao, L. Yu, J. S. Lindsey, D. F. Bocian and V. Misra, Adv. Mater., 2004 16, 133-137.

23 S. B. Roscoe, A. K. Kakkar, T. J. Marks, A. Malik, M. K. Durbin, W. Lin, G. K. Wong and P. Dutta, Langmuir, 1996, 12, 4218-4223.

24 G. Lee, L. Chrisey and R. Colton, Science, 1994, 266, 771-773.

25 M. J. Schöning and H. Lüth, Phys. Status Solidi A, 2001, 185, 65-77.

26 J. Sagiv, J. Am. Chem. Soc., 1980, 102, 92-98.

27 L. T. Zhuravlev, Langmuir, 1987, 3, 316-318.

28 K. Bierbaum, M. Kinzler, C. Woell, M. Grunze, G. Haehner, S. Heid and F. Effenberger, Langmuir, 1995, 11, 512-518.

29 S. R. Wasserman, Y. T. Tao and G. M. Whitesides, Langmuir, 1989, 5, 1074-1087.

30 N. Tillman, A. Ulman, J. S. Schildkraut and T. L. Penner, J. Am. Chem. Soc., 1988, 110, 6136-6144.

31 R. Tian, O. Seitz, M. Li, W. Hu, Y. J. Chabal and J. Gao, Langmuir, 2010, 26, 4563-4566.

32 S. Onclin, B. J. Ravoo and D. N. Reinhoudt, Angew. Chem., Int. Ed., 2005, 44, 6282-6304.

33 N. Rozlosnik, M. C. Gerstenberg and N. B. Larsen, Langmuir, 2003, 19, 1182-1188.

34 Y. Wang and M. Lieberman, Langmuir, 2003, 19, 1159-1167.

35 R. M. Pasternack, S. Rivillon Amy and Y. J. Chabal, Langmuir, 2008, 24, 12963-12971.

36 J. D. Le Grange, J. L. Markham and C. R. Kurkjian, Langmuir, 1993, 9, 1749-1753.

37 T. Vallant, H. Brunner, U. Mayer, H. Hoffmann, T. Leitner, R. Resch and G. Friedbacher, J. Phys. Chem. B, 1998, 102, 7190-7197.

38 P. Silberzan, L. Leger, D. Ausserre and J. J. Benattar, Langmuir, 1991, 7, 1647-1651.

39 C. D. Bain, E. B. Troughton, Y. T. Tao, J. Evall, G. M. Whitesides and R. G. Nuzzo, J. Am. Chem. Soc., 1989, 111, 321-335.

40 M. D. Porter, T. B. Bright, D. L. Allara and C. E. D. Chidsey, J. Am. Chem. Soc., 1987, 109, 3559-3568.

41 C. D. Bain and G. M. Whitesides, J. Am. Chem. Soc., 1988, 110, 6560-6561

42 M. Hasan, D. Bethell and M. Brust, J. Am. Chem. Soc., 2002, 124, 1132-1133.

43 C. Vericat, M. E. Vela and R. C. Salvarezza, Phys. Chem. Chem. Phys., 2005, 7, 3258-3268.

44 G. Yang, N. A. Amro, Z. B. Starkewolfe and G.-y. Liu, Langmuir, 2004, 20, 3995-4003.

45 E. Cortés, A. A. Rubert, G. Benitez, P. Carro, M. E. Vela and R. C. Salvarezza, Langmuir, 2009, 25, 5661-5666.

46 H. O. Finklea, S. Avery, M. Lynch and T. Furtsch, Langmuir, 1987, 3, 409-413.

47 W. R. Everett, T. L. Welch, L. Reed and I. Fritsch-Faules, Anal. Chem., 1995, 67, 292-298.

48 N. Garg, E. Carrasquillo-Molina and T. R. Lee, Langmuir, 2002, 18, 2717-2726. 
49 A. B. Horn, D. A. Russell, L. J. Shorthouse and T. R E. Simpson, J. Chem. Soc., Faraday Trans., 1996, 92, 4759-4762.

50 D. A. Hutt and G. J. Leggett, J. Phys. Chem., 1996, 100, 6657-6662.

51 E. Cooper and G. J. Leggett, Langmuir, 1998, 14, 4795-4801.

52 M. H. Schoenfisch and J. E. Pemberton, J. Am. Chem. Soc., 1998, 120, 4502-4513.

53 R. D. English, M. J. Van Stipdonk, R. C. Sabapathy, R. M. Crooks and E. A. Schweikert, Anal. Chem., 2000, 72, 5973-5980.

$54 \mathrm{~W}$. Yang, E. Chow, G. D. Willett, D. B. Hibbert and J. J. Gooding, Analyst, 2003, 128, 712-718.

55 W. R. Yang, D. B. Hibbert, R. Zhang, G. D. Willett and J. J. Gooding, Langmuir, 2004, 21, 260-265.

56 E. Chow, D. B. Hibbert and J. J. Gooding, Anal. Chim. Acta, 2005, 543, 167-176.

57 F. J. Mearns, E. L. S. Wong, K. Short, D. B. Hibbert and J. J. Gooding, Electroanalysis, 2006, 18, 1971-1981.

58 J. J. Gooding, A. Chou, F. J. Mearns, E. Wong and K. L. Jericho, Chem. Commun., 2003, 1938-1939.

59 K. Bandyopadhyay, H. Liu, S.-G. Liu and L. Echegoyen, Chem. Commun., 2000, 141-142.

60 M. Akram, M. C. Stuart and D. K. Y. Wong, Anal. Chim. Acta, 2004, 504, 243-251.

61 Y. Zhao, W. Pérez-Segarra, Q. Shi and A. Wei, J. Am. Chem. Soc., 2005, 127, 7328-7329.

62 S. Roux, B. Garcia, J.-L. Bridot, M. Salomé, C. Marquette, L. Lemelle, P. Gillet, L. Blum, P. Perriat and O. Tillement, Langmuir, 2005, 21, 2526-2536.

63 L. Guerrini, J. V. Garcia-Ramos, C. Domingo and S. Sanchez-Cortes, Langmuir, 2006, 22, 10924-10926.

64 D. T. Gryko, F. Zhao, A. A. Yasseri, K. M. Roth, D. F. Bocian, W. G. Kuhr and J. S. Lindsey, J. Org. Chem., 2000, 65, 7356-7362.

65 P. K. Eggers, D. B. Hibbert, M. N. Paddon-Row and J. J. Gooding, J. Phys. Chem. C, 2009, 113, 8964-8971.

66 J. P. Collman, N. K. Devaraj, R. A. Decreau, Y. Yang, Y.-L. Yan, W. Ebina, T. A. Eberspacher and C. E. D. Chidsey, Science, 2007, 315, 1565-1568.

67 Q. Yang, C. Kaul and M. Ulbricht, Langmuir, 2010, 26, $5746-5752$

68 Y. Xiao, F. Patolsky, E. Katz, J. F. Hainfeld and I. Willner, Science, 2003, 299, 1877-1881.

69 J. Mazurkiewicz, F. J. Mearns, D. Losic, L. Weeks, E. R. Waclawik, C. T. Rogers, J. G. Shapterd and J. J. Gooding, J. Vac. Sci. Technol., B, 2002, 20, 2265-2270.

70 R. Boukherroub, Curr. Opin. Solid State Mater. Sci., 2005, 9, 66-72.

71 J. M. Buriak, Chem. Commun., 1999, 1051-1060.

72 S. Ciampi, J. B. Harper and J. J. Gooding, Chem. Soc. Rev., 2010, 39, 2158-2183.

73 K. A. Kilian, T. Böcking, K. Gaus, M. Gal and J. J. Gooding, Biomaterials, 2007, 28, 3055-3062.

74 A. Salomon, T. Bocking, J. Gooding and D. Cahen, Nano Lett., 2006, 6, 2873-2876.

75 T. Böcking, K. A. Kilian, K. Gaus and J. J. Gooding, Adv. Funct. Mater., 2008, 18, 3827-3833.

76 L. Nebhani and C. Barner-Kowollik, Adv. Mater., 2009, 21, 3442-3468.

77 R. Boukherroub, S. Morin, P. Sharpe, D. D. M. Wayner and P. Allongue, Langmuir, 2000, 16, 7429-7434.

78 T. Strother, R. J. Hamers and L. M. Smith, Nucleic Acids Res., 2000, 28, 3535-3541.

79 H. Jin, C. R. Kinser, P. A. Bertin, D. E. Kramer, J. A. Libera, M. C. Hersam, S. T. Nguyen and M. J. Bedzyk, Langmuir, 2004, 20, 6252-6258

80 M. R. Linford and C. E. D. Chidsey, J. Am. Chem. Soc., 1993, 115, 12631-12632.

81 Y. Cai and B. P. Roberts, Tetrahedron Lett., 2001, 42, 4581-4584.

82 R. Boukherroub, J. T. C. Wojtyk, D. D. M. Wayner and D. J. Lockwood, J. Electrochem. Soc., 2002, 149, H59-H63.

83 F. Cattaruzza, A. Cricenti, A. Flamini, M. Girasole, G. Longo, A. Mezzi and T. Prosperi, J. Mater. Chem., 2004, 14, $1461-1468$
84 D. Zigah, C. Herrier, L. Scheres, M. Giesbers, B. Fabre, P. Hapiot and H. Zuilhof, Angew. Chem., Int. Ed., 2010, 49, $3157-3160$

85 A. Faucheux, A. C. Gouget-Laemmel, C. Henry de Villeneuve, R. Boukherroub, F. Ozanam, P. Allongue and J.-N. Chazalviel, Langmuir, 2005, 22, 153-162.

86 M. Perring, S. Dutta, S. Arafat, M. Mitchell, P. J. A. Kenis and N. B. Bowden, Langmuir, 2005, 21, 10537-10544.

87 S. Sam, L. Touahir, J. Salvador Andresa, P. Allongue, J. N. Chazalviel, A. C. Gouget-Laemmel, C. Henry de Villeneuve, A. Moraillon, F. Ozanam, N. Gabouze and S. Djebbar, Langmuir, 2010, 26, 809-814.

88 R. Voicu, R. Boukherroub, V. Bartzoka, T. Ward, J. T. C. Wojtyk and D. D. M. Wayner, Langmuir, 2004, 20, 11713-11720.

89 T. Böcking, E. L. S. Wong, M. James, J. A. Watson, C. L. Brown, T. C. Chilcott, K. D. Barrow and H. G. L. Coster, Thin Solid Films, 2006, 515, 1857-1863.

90 B. Fabre and F. Hauquier, J. Phys. Chem. B, 2006, 110, $6848-6855$

91 K. A. Kilian, T. Böcking, K. Gaus and J. J. Gooding, Angew. Chem., Int. Ed., 2008, 47, 2697-2699.

92 F. Cattaruzza, A. Cricenti, A. Flamini, M. Girasole, G. Longo, T. Prosperi, G. Andreano, L. Cellai and E. Chirivino, Nucleic Acids Res., 2006, 34, e32.

93 H. B. Yin, T. Brown, R. Greef, J. S. Wilkinson and T. Melvin, Microelectron. Eng., 2004, 73-74, 830-836.

94 S. A. Mitchell, T. R. Ward, D. D. M. Wayner and G. P. Lopinski, J. Phys. Chem. B, 2002, 106, 9873-9882.

95 A. Moraillon, A. C. Gouget-Laemmel, F. Ozanam and J. N. Chazalviel, J. Phys. Chem. C, 2008, 112, 7158-7167.

96 M. Delamar, R. Hitmi, J. Pinson and J. M. Saveant, J. Am. Chem. Soc., 1992, 114, 5883-5884.

97 A. J. Downard, Electroanalysis, 2000, 12, 1085-1096.

98 J. Pinson and F. Podvorica, Chem. Soc. Rev., 2005, 34, 429-439.

99 A. Sinitskii, A. Dimiev, D. A. Corley, A. A. Fursina, D. V. Kosynkin and J. M. Tour, ACS Nano, 2010, 4, 1949-1954.

100 M.-C. Bernard, A. Chaussé, E. Cabet-Deliry, M. M. Chehimi, J. Pinson, F. Podvorica and C. Vautrin-Ul, Chem. Mater., 2003, 15, 3450-3462.

101 P. Allongue, C. H. de Villeneuve, G. Cherouvrier, R. Cortes and M. C. Bernard, J. Electroanal. Chem., 2003, 550-551, 161-174.

102 M. P. Stewart, F. Maya, D. V. Kosynkin, S. M. Dirk, J. J. Stapleton, C. L. McGuiness, D. L. Allara and J. M. Tour, J. Am. Chem. Soc., 2003, 126, 370-378.

103 T. He, J. He, M. Lu, B. Chen, H. Pang, W. F. Reus, W. M. Nolte, D. P. Nackashi, P. D. Franzon and J. M. Tour, J. Am. Chem. Soc., 2006, 128, 14537-14541.

104 S. Maldonado, T. J. Smith, R. D. Williams, S. Morin, E. Barton and K. J. Stevenson, Langmuir, 2006, 22, 2884-2891.

105 J. L. Bahr, J. Yang, D. V. Kosynkin, M. J. Bronikowski, R. E. Smalley and J. M. Tour, J. Am. Chem. Soc., 2001, 123, 6536-6542.

106 C. A. Dyke and J. M. Tour, J. Am. Chem. Soc., 2003, 125, $1156-1157$.

107 C. Saby, B. Ortiz, G. Y. Champagne and D. Bélanger, Langmuir, 1997, 13, 6805-6813.

108 J. Lehr, B. E. Williamson, B. S. Flavel and A. J. Downard, Langmuir, 2009, 25, 13503-13509.

109 K. Boukerma, M. M. Chehimi, J. Pinson and C. Blomfield, Langmuir, 2003, 19, 6333-6335.

110 S. Boland, F. d. r. Barrière and D. n. Leech, Langmuir, 2008, 24, 6351-6358.

111 A. Gui, G. Liu, M. Chockalingam, G. Le Saux, J. Harper and J. Gooding, Electroanalysis, 2010, 22, 1283-1289.

112 L. Civit, A. Fragoso and C. K. O'Sullivan, Electrochem. Commun., 2010, 12, 1045-1048

113 A. Adenier, C. Combellas, F. Kanoufi, J. Pinson and F. I. Podvorica, Chem. Mater., 2006, 18, 2021-2029.

114 C. Combellas, F. Kanoufi, J. Pinson and F. I. Podvorica, J. Am. Chem. Soc., 2008, 130, 8576-8577.

115 J. M. Chrétien, M. Ghanem, P. Bartlett and J. Kilburn, Chem.-Eur. J., 2008, 14, 2548-2556.

116 J. J. Gooding, Electroanalysis, 2008, 20, 573-582.

117 S. Baranton and D. Bélanger, J. Phys. Chem. B, 2005, 109, 24401-24410. 
118 G. Liu, M. Chockalingham, S. Khor, A. Gui and J. Gooding, Electroanalysis, 2010, 22, 918-926.

119 G. Liu, J. Liu, T. Böcking, P. K. Eggers and J. J. Gooding, Chem. Phys., 2005, 319, 136-146.

120 G. Z. Liu and J. J. Gooding, Langmuir, 2006, 22, 7421-7430.

121 C. Louault, M. D'Amours and D. Bélanger, ChemPhysChem, 2008, 9, 1164-1170.

122 J. Liu, M. N. Paddon-Row and J. J. Gooding, J. Phys. Chem. B, 2004, 108, 8460-8466.

123 C. E. D. Chidsey, C. R. Bertozzi, T. M. Putvinski and A. M. Mujsce, J. Am. Chem. Soc., 1990, 112, 4301-4306.

124 S. B. Sachs, S. P. Dudek, R. P. Hsung, L. R. Sita, J. F. Smalley, M. D. Newton, S. W. Feldberg and C. E. D. Chidsey, J. Am. Chem. Soc., 1997, 119, 10563-10564.

125 J. F. Smalley, S. W. Feldberg, C. E. D. Chidsey, M. R. Linford, M. D. Newton and Y.-P. Liu, J. Phys. Chem., 1995, 99, 13141-13149.

126 Y. Wang, X. Yao, J. Wang and F. Zhou, Electroanalysis, 2004, 16, 1755-1761

127 K. Weber and S. E. Creager, Anal. Chem., 1994, 66, 3164-3172.

128 B. Guan, A. Magenau, K. A. Kilian, S. Ciampi, K. Gaus, P. J. Reece and J. J. Gooding, Faraday Discuss., 2011, 149, 301-317.

129 V. S.-Y. Lin, K. Motesharei, K.-P. S. Dancil, M. J. Sailor and M. R. Ghadiri, Science, 1997, 278, 840-843.

130 K. A. Kilian, T. Böcking and J. J. Gooding, Chem. Commun., 2009, 630-640.

131 K. A. Kilian, T. Böcking, K. Gaus, M. Gal and J. J. Gooding, ACS Nano, 2007, 1, 355-361.

132 M. Rosso, M. Giesbers, K. Schroën and H. Zuilhof, Langmuir, 2010, 26, 866-872.

133 D. Sehgal and I. K. Vijay, Anal. Biochem., 1994, 218, 87-91.

134 N. Zammatteo, L. Jeanmart, S. Hamels, S. Courtois, P. Louette, L. Hevesi and J. Remacle, Anal. Biochem., 2000, 280, $143-150$.

135 D. G. Kurth and T. Bein, Langmuir, 1993, 9, 2965-2973.

136 J. V. Staros, R. W. Wright and D. M. Swingle, Anal. Biochem., 1986, 156, 220-222.

137 L. Jiang, A. Glidle, A. Griffith, C. J. McNeil and J. M. Cooper, Bioelectrochem. Bioenerg., 1997, 42, 15-23.

138 F. Wei, B. Sun, Y. Guo and X. S. Zhao, Biosens. Bioelectron., 2003, 18, 1157-1163.

139 Z. Lin, T. Strother, W. Cai, X. Cao, L. M. Smith and R. J. Hamers, Langmuir, 2002, 18, 788-796.

140 H. G. Hong, M. Jiang, S. G. Sligar and P. W. Bohn, Langmuir, 1994, 10, 153-158.

141 H. G. Hong, P. W. Bohn and S. G. Sligar, Anal. Chem., 1993, 65, $1635-1638$.

142 J. D. Gregory, J. Am. Chem. Soc., 1955, 77, 3922-3923.

143 S. K. Bhatia, L. C. Shriver-Lake, K. J. Prior, J. H. Georger, J. M. Calvert, R. Bredehorst and F. S. Ligler, Anal. Biochem., 1989, 178, 408-413.
144 C. W. Tornøe, C. Christensen and M. Meldal, J. Org. Chem., 2002, 67, 3057-3064.

145 V. V. Rostovtsev, L. G. Green, V. V. Fokin and K. B. Sharpless, Angew. Chem., Int. Ed., 2002, 41, 2596-2599.

146 V. D. Bock, H. Hiemstra and J. H. van Maarseveen, Eur. J. Org. Chem., 2006, 51-68.

147 N. K. Devaraj and J. P. Collman, QSAR Comb. Sci., 2007, 26, 1253-1260.

148 H. C. Kolb and K. B. Sharpless, Drug Discovery Today, 2003, 8, $1128-1137$.

149 J. P. Collman, N. K. Devaraj, T. P. A. Eberspacher and C. E. D. Chidsey, Langmuir, 2006, 22, 2457-2464.

150 J. P. Collman, N. K. Devaraj and C. E. D. Chidsey, Langmuir, 2004, 20, 1051-1053.

151 S. Ciampi, T. Böcking, K. A. Kilian, J. B. Harper and J. J. Gooding, Langmuir, 2008, 24, 5888-5892.

152 N. D. Gallant, K. A. Lavery, E. J. Amis and M. L. Becker, Adv. Mater., 2007, 19, 965-969.

153 M. Fischler, A. Sologubenko, J. Mayer, G. Clever, G. Burley, J. Gierlich, T. Carell and U. Simon, Chem. Commun., 2008, 169-171.

154 X.-L. Sun, C. L. Stabler, C. S. Cazalis and E. L. Chaikof, Bioconjugate Chem., 2005, 17, 52-57.

155 H. Liu, F. Duclairoir, B. Fleury, L. Dubois, Y. Chenavier and J.-C. Marchon, Dalton Trans., 2009, 3793-3799.

156 D. A. Fleming, C. J. Thode and M. E. Williams, Chem. Mater., 2006, 18, 2327-2334.

157 S. Ciampi, T. Böcking, K. A. Kilian, M. James, J. B. Harper and J. J. Gooding, Langmuir, 2007, 23, 9320-9329.

158 S. Ciampi, G. Le Saux, J. B. Harper and J. J. Gooding, Electroanalysis, 2008, 20, 1513-1519.

159 S. Ciampi, P. K. Eggers, G. Le Saux, M. James, J. B. Harper and J. J. Gooding, Langmuir, 2009, 25, 2530-2539.

$160 \mathrm{H}$. A. Latham-Timmons, A. Wolter, J. S. Roach, R. Giare and M. Leuck, Nucleosides, Nucleotides Nucleic Acids, 2003, 22, $1495-1497$.

161 B. T. Houseman and M. Mrksich, Chem. Biol., 2002, 9, 443-454.

162 B. T. Houseman, J. H. Huh, S. J. Kron and M. Mrksich, Nat. Biotechnol., 2002, 20, 270-274.

163 P. T. Dirlam, G. A. Strange, J. A. Orlicki, E. D. Wetzel and P. J. Costanzo, Langmuir, 2010, 26, 3942-3948.

164 Y. Kwon and M. Mrksich, J. Am. Chem. Soc., 2002, 124, 806-812.

165 P. Siemsen, R. C. Livingston and F. Diederich, Angew. Chem., Int. Ed., 2000, 39, 2632-2657.

166 M. Rist, N. Amann and H.-A. Wagenknecht, Eur. J. Org. Chem., 2003, 2498-2504.

167 J. Li, P. S. Thiara and M. Mrksich, Langmuir, 2007, 23, $11826-11835$.

168 J.-C. Lin, J.-H. Kim, J. A. Kellar, M. C. Hersam, S. T. Nguyen and M. J. Bedzyk, Langmuir, 2010, 26, 3771-3773.

169 S. Ciampi, M. James, N. Darwish, E. Luais, B. Guan, J. B. Harper and J. J. Gooding, in preparation. 